\title{
Pile heat exchangers: thermal behaviour and interactions
}

Fleur Loveridge MSc, FGS, CGeol, CEng, MICE Research Fellow, Faculty of Engineering and the Environment, University of Southampton, UK
William Powrie MA, MSc, PhD, CEng, FREng, FICE Professor of Geotechnical Engineering and Dean of the Faculty of Engineering and the Environment, University of Southampton, UK

Thermal piles - that is structural foundation piles also used as heat exchangers as part of a ground energy system - are increasingly being adopted for their contribution to more sustainable energy strategies for new buildings. Despite over a quarter of a century having passed since the installation of the first thermal piles in northern Europe, uncertainties regarding their behaviour remain. This paper identifies the key factors which influence the heat transfer and thermal-mechanical interactions of such piles. In terms of heat output, pile aspect ratio is identified as an important parameter controlling the overall thermal performance. Temperature changes in the concrete and surrounding ground during thermal pile operation will lead to additional concrete stresses and displacements within the pile-soil system. Consequently designers must ensure that temperatures remain within acceptable limits, while the pile geotechnical analysis should demonstrate that any adverse thermal stresses are within design safety factors and that any additional displacements do not affect the serviceability of the structure.

\section{Notation}

A area $\left(\mathrm{m}^{2}\right)$

$F \quad$ dimensionless temperature response function

$G$ temperature response function for an infinite cylindrical heat source

$H \quad$ pile or borehole length (m)

$h \quad$ heat transfer coefficient $\left(\mathrm{W} /\left(\mathrm{m}^{2} \mathrm{~K}\right)\right)$

$L \quad$ thickness of material $(\mathrm{m})$

$m \quad$ mass flow rate $(\mathrm{kg} / \mathrm{s})$

$Q \quad$ rate of heat transfer (W)

$q \quad$ rate of heat transfer per unit length $(\mathrm{W} / \mathrm{m})$

$R \quad$ thermal resistance (K/W in conjunction with $\mathrm{Q}$ or $\mathrm{mK} / \mathrm{W}$ in conjunction with q)

$r \quad$ radial coordinate $(\mathrm{m})$

$S_{\mathrm{c}} \quad$ specific heat capacity $(\mathrm{J} /(\mathrm{kg} \mathrm{K}))$

$T$ temperature (K)

$t \quad$ time (s)

$x \quad$ distance, length along pipe circuit (m)

$\alpha \quad$ thermal diffusivity $\left(\mathrm{m}^{2} / \mathrm{s}\right)$

$\gamma \quad$ Euler's constant

$\Delta \quad$ change in value (usually temperature)

$\lambda \quad$ thermal conductivity $(\mathrm{W} /(\mathrm{m} \mathrm{K}))$

\section{Subscripts}

$\mathrm{b}$ borehole wall pile diameter

concrete

conductive

fluid

ground

internal diameter

inlet

o outer diameter
p pipe

\section{Introduction}

Rising energy prices and government policy drivers are leading to an increase in the use of ground energy systems to contribute to the heating and cooling requirements of new buildings (Preene and Powrie, 2009). Thermal piles are a specialist type of closedloop ground energy system in which small-diameter pipes are cast into the piled foundations of a building to allow circulation of a heat transfer fluid. For rotary bored piles with a full depth cage, the pipes are usually fixed to the pile cage either during prefabrication, or on site if the cage comes in sections (Figure 1(a)). For continuous flight auger (CFA) piles, or piles where the cage is less than full depth, it is common to plunge the pipe loops into the centre of the concrete, often attached to a steel bar to provide sufficient rigidity to facilitate installation of the loop within the pile (Figure 1(b)).

Below the upper few metres, the ground is essentially of constant temperature throughout the year (Figure 2). Hence in winter, circulation of cooler fluid within thermal piles allows heat extraction from the surrounding ground and in summer, circulation of warmer fluid allows injection of excess heat into the ground. A heat pump enables the temperature of the heated fluid to be increased to a more useful level by the input of a small amount of electrical energy. Similarly, in cooling mode, a heat pump allows a reduction in fluid temperature to below that used in the air-conditioning system, increasing the effectiveness of heat transfer on reinjection into the ground. Operation philosophies may differ, as described below. 


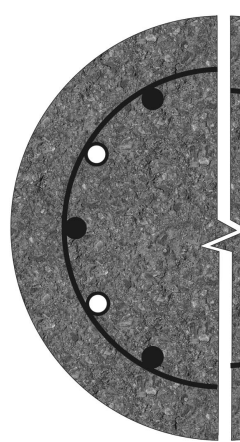

Pipes installed inside prefabricated steel cage

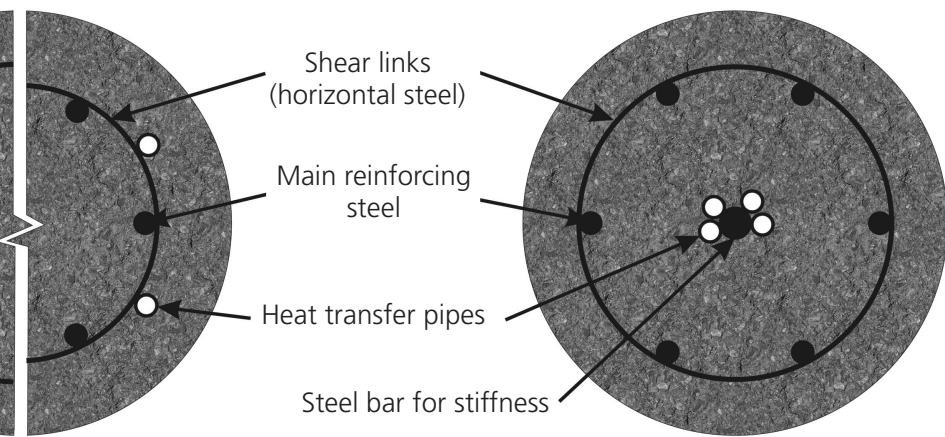

Pipes installed

outside cage during contruction

(a)
Pipes and steel bar plunged into centre of pile after conrcete is poured

(b)

Figure 1. Typical thermal pile construction details: (a) pipework fixed to a rotary bored pile cage; (b) pipework installed in the centre of a pile

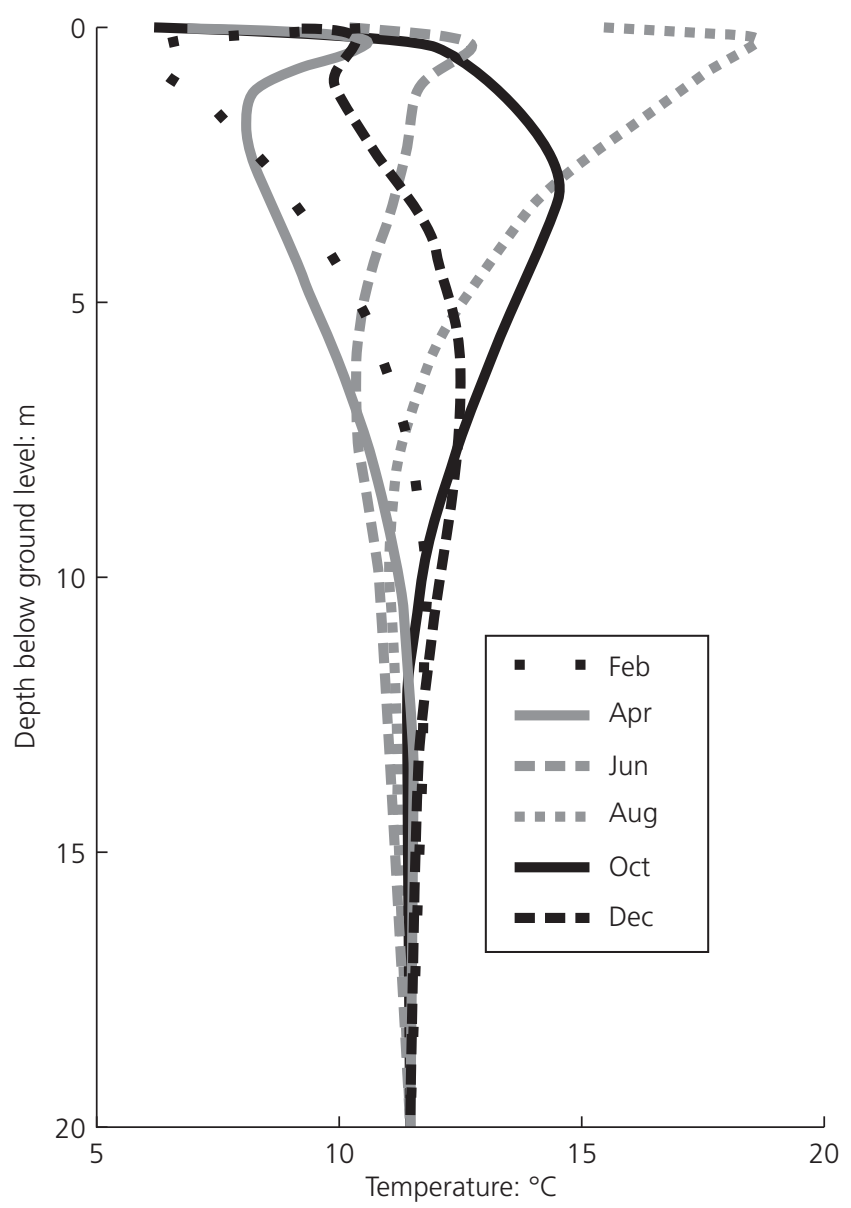

Figure 2. Typical near-surface seasonal temperature variation (calculated numerically assuming dry bulb air temperature profile for London, UK (CIBSE, 2005) and $\alpha=1.875 \times 10^{-6} \mathrm{~m}^{2} / \mathrm{s}$ ) (a) For small or domestic properties there is usually only a heating demand, which is met in conjunction with a heat pump. Heat transfer is unidirectional and systems must be designed to prevent excessive temperatures developing in the ground.

(b) For larger structures, which have both heating and cooling needs, it is advantageous to balance these and make use of inter-seasonal ground energy storage. This allows greater thermal efficiency between the same ground temperature limits. In this case the heat pump must be reversible.

(c) In some circumstances it is possible to adopt so-called 'free cooling' whereby warm fluid is returned to the ground heat exchangers without passing through a heat pump. If temperatures allow, this mode of operation is highly efficient.

Ground energy systems have been in use for decades, with significant take-up (particularly in northern Europe and North America) commencing in the 1970 s due to increasing oil prices. Many ground energy systems use drilled boreholes as heat exchangers and research into these systems was pioneered in the 1980s in Scandinavia (e.g. Eskilson, 1987) and North America (e.g. Bose et al., 1985). The first thermal piles were installed in the 1980s (Brandl, 2006), but while design methods for borehole heat exchangers (BHEs) have matured, research into the behaviour of thermal piles has been more limited. In addition, coupling the structural and heat exchange functions of a pile means that the impact of thermal changes in the pile on its load-bearing capacity needs to be addressed. Standard design methods for either the thermal or the geotechnical aspects are not yet available and few sources of guidance are published (NHBC, 2010; SIA, 2005).

This paper sets out the underlying thermodynamic concepts relevant to thermal pile performance. It then outlines the key 
thermal design aspects for BHEs. This is important as these approaches are often used as a basis for assessing the heat output of thermal piles. Lessons learnt from the study of BHEs are then used to help understand the key factors controlling pile thermal behaviour. The paper then examines the interactions between thermal behaviour and mechanical performance of thermal piles, before introducing some more practical issues that must be considered. Finally knowledge gaps and areas where further research is required are identified.

\section{Heat transfer concepts}

Thermal piles, like other ground energy systems, function through the transfer of heat by way of conduction and convection. Conduction, due to the movement of atomic particles, is the primary heat transfer mechanism in solids. It is also referred to as diffusion. Convection is actually two heat transfer mechanisms: diffusion and the bulk movement of a fluid, termed advection. Convection is referred to as forced when the fluid flow is driven by external forces such as pumps. The flow may be internal (e.g. within a pipe) or external (e.g. around a fixed body).

Figure 3 illustrates a simplified heat transfer pathway for a thermal pile from the heat transfer fluid through to the ground. Forced convection occurs by way of the internal flow in the pipes; conduction occurs across the pipe walls and through the concrete to the ground. In the ground, conduction is usually the dominant process (Rees et al., 2000), but if groundwater is flowing then advection can also be important (Chiasson et al., 2000).

All convection is described by Newton's law of cooling, which relates the rate of heat transfer $(Q$, measured in $\mathrm{W})$ per unit area $\left(A\right.$ in $\mathrm{m}^{2}$ ) to the temperature difference (in $\mathrm{K}$ ) across the convection surface and a heat transfer coefficient, $h$ (in $\mathrm{W} / \mathrm{m}^{2} \mathrm{~K}$ ). Thus for heat transfer between the heat exchange fluid in the pipes and the pipe wall

$$
\text { 1. } \frac{Q}{A}=h\left(T_{\mathrm{pi}}-T_{\mathrm{f}}\right)
$$

The value of $h$ will depend on the properties of the heat transfer fluid, the nature of the flow conditions and the size of the pipe (e.g. Coulson and Richardson, 1990; Hellstrom, 1991). For water with turbulent flow the value of $h$ is typically between 1000 and 3000 depending on the Reynolds number. There will be some degree of temperature dependency, but this is small and the impact on heat transfer is normally neglected. For laminar flow the heat transfer coefficient is an order of magnitude less than for turbulent conditions.

For steady heat conduction in one dimension, Fourier's law describes the relationship between the heat transfer rate and the temperature profile. Fourier's law is analogous to Darcy's law

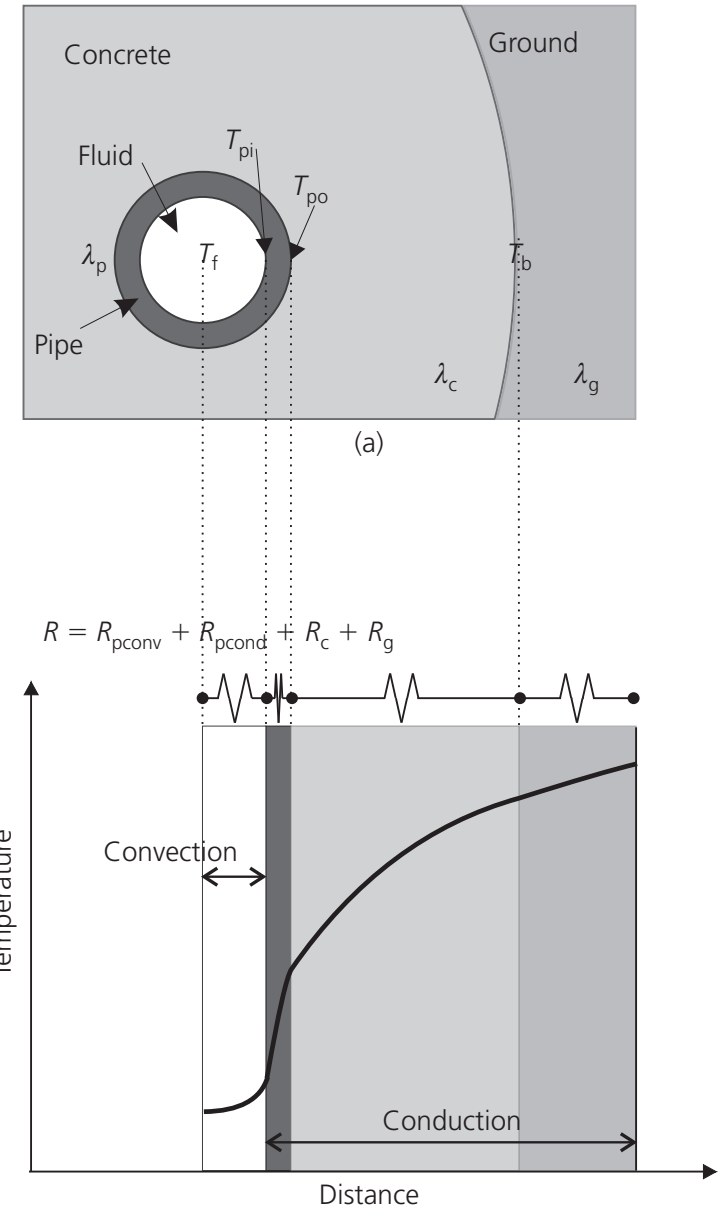

(b)

Figure 3. Thermal pile heat transfer concepts: (a) plan of thermal pile components; (b) temperature differences and component resistances

(Table 1) for groundwater flow, and for a temperature difference $\Delta T$ over a length $L$

2. $\frac{Q}{A}=-\lambda \frac{\Delta T}{L}$

The constant of proportionality $\lambda$ is the thermal conductivity (in $\mathrm{W} / \mathrm{m} \mathrm{K}$ ) and is a measure of how well a substance conducts heat. It is analogous to the Darcy hydraulic conductivity and to electrical conductance. Hence a resistance to heat transfer, $R$ (in $\mathrm{K} / \mathrm{W}$ ), can also be defined

3. $R=\frac{\Delta T}{|Q|}=\frac{L}{A \lambda}$

Thermal resistance is a useful concept, as like electrical resis- 


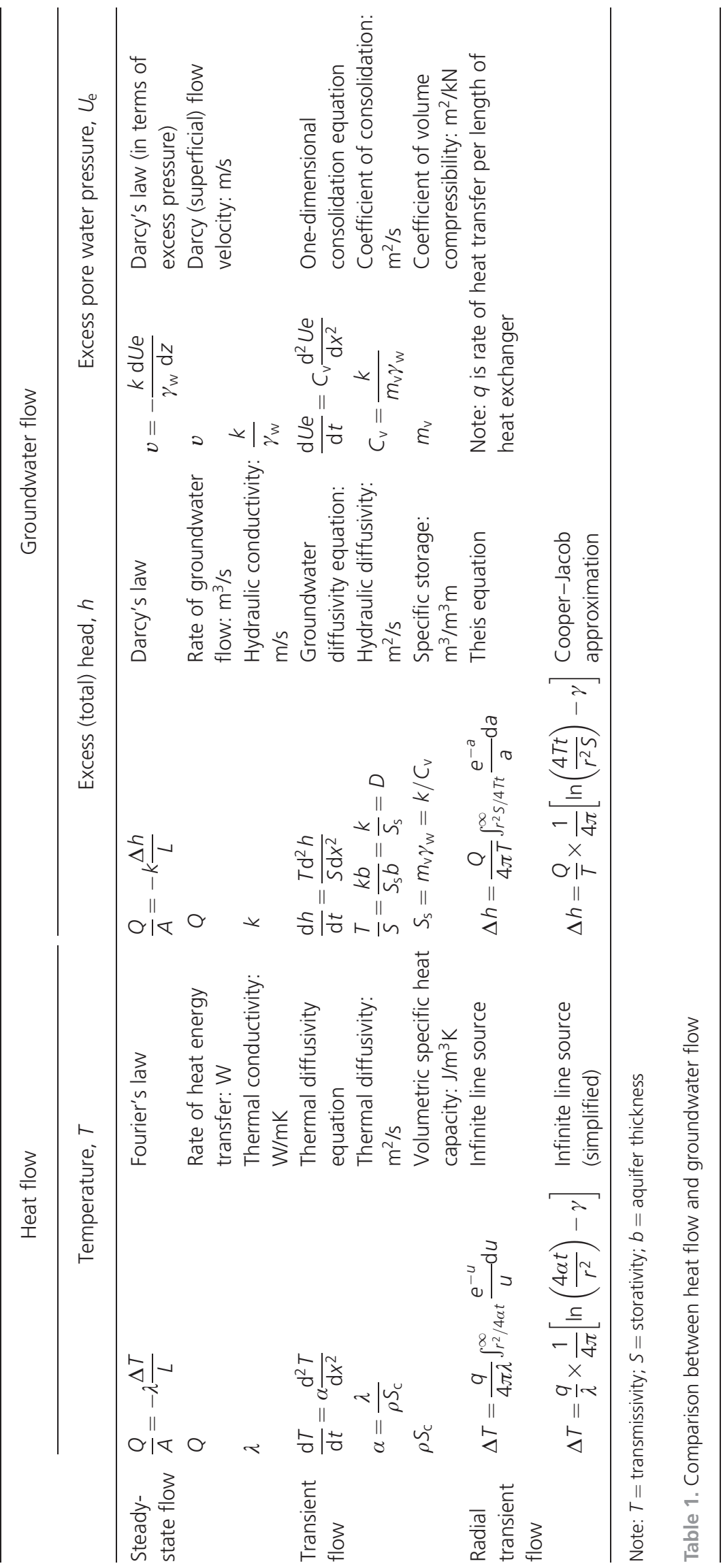


tance, the component resistances of a system in series may be added to give an overall resistance (Figure 3(b)). The concept of resistance can also be used for convection, in which case

$$
\text { 4. } \quad R=\frac{\Delta T}{|Q|}=\frac{1}{h A}
$$

While heat transfer within a heat exchanger is often assumed to be at steady state and therefore considered in terms of its resistance, the response in the ground is usually transient. In transient conditions, heat transfer depends not only on the combination of thermal conductivity and geometry (i.e. resistance) but also on the speed at which temperatures change. This in turn is governed by the specific heat capacity of the ground, $S_{\mathrm{C}}$ (the amount of heat released per unit mass for a one degree change in temperature). Transient conduction is described by the diffusion equation, which is analogous to the groundwater diffusion equation (Table 1) and relates the change in temperature with time to the temperature gradient

5. $\quad \frac{\mathrm{d} T}{\mathrm{~d} t}=\alpha \frac{\mathrm{d}^{2} T}{\mathrm{~d} x^{2}}$

where $\alpha$ is the thermal diffusivity in $\mathrm{m}^{2} / \mathrm{s}$ and is a measure of how quickly a material responds to a change in the temperature regime. $\alpha$ can also be expressed as $\alpha=\lambda / \rho S_{\mathrm{c}}$ where $\rho$ is the density. Extending the groundwater flow analogy, the thermal diffusivity can be considered to be equivalent to the hydraulic diffusivity in aquifer terminology or the coefficient of consolidation in consolidation theory (Table 1). Thermal conductivity and thermal diffusivity (or specific heat capacity) are the key ground parameters required for design ground energy systems, and are discussed by Busby et al. (2009), VDI (2009), Banks (2008) and Kavanaugh and Rafferty (1997).

In practice, the heat transfer occurring within a thermal pile is more complex than is shown in Figure 3. The heat transfer pathway is not simply linear and it is possible for the different pipes to exchange heat with each other as well as with the ground by way of the concrete. In addition, where there is a change of material type, and the interface between those materials is imperfect, additional resistance to heat flow is provided by 'contact resistance'. The major complexities are discussed further in the following sections.

\section{Thermal performance of borehole heat exchangers}

Borehole heat exchangers have a number of similarities to thermal piles, but also some significant differences. Consequently lessons can be learnt from the extensive research and experience on borehole design methods, as long as these are tempered with an understanding of the key differences in behaviour which will be discussed in Section 4. This section sets out some important concepts relevant to BHE behaviour. These concepts will then be extended for thermal piles in Section 4.

In the assessment of BHEs, the external response of the ground and the internal response of the heat exchanger are usually considered separately. Assuming steady state conditions in the borehole, the temperature change across the borehole and the temperature change in the ground can be summed as follows

6. $\quad T_{\mathrm{f}}-T_{0}=\Delta T_{\text {borehole }}+\Delta T_{\text {ground }}=q R_{\mathrm{b}}+\frac{q}{\lambda} F$

where $T_{\mathrm{f}}$ is the temperature of the circulating fluid and $T_{0}$ is the initial temperature in the ground. $q$ is the rate of heat transfer per unit length and $R_{\mathrm{b}}$ is the borehole thermal resistance (in $\mathrm{m} \mathrm{K} / \mathrm{W}$ ). $F$ is a transient temperature response function, which describes the transient change in temperature in the ground in response to $q . F$ is a function of time, distance and thermal diffusivity, but is of the same mathematical form for a given geometry. Thus the shape of the temperature response curve is independent of the actual temperatures and heat transfer rate. This type of behaviour is common to many heat transfer problems and lends itself to dimensionless analysis.

\subsection{External response}

The simplest method of calculating the ground thermal response is to consider the borehole to be an infinitely long line heat source (ILS) within an infinite medium. This is analogous to the radial flow of groundwater to a well (Table 1). As in the Theis equation, assuming a constant flux $q$, the temperature response function due to the heat source can be simplified to a log-linear relationship (Figure 4). The response function then becomes (Carslaw and Jaeger, 1959)

7. $\Delta T=\frac{q}{\lambda} \times \frac{1}{4 \pi}\left[\ln \left(\frac{4 \alpha t}{r^{2}}\right)-\gamma\right]$

However, at small times the ILS approach will underestimate the temperature response. This is because it assumes that the heat source is at the centre of the borehole rather than the circumference. This shortcoming can be addressed by modelling the borehole as an infinite cylindrical heat source (ICS). The analytical solution for the temperature response function for the ICS is more complex (Ingersoll et al., 1954), but a simpler curvefitted version can be used (Bernier, 2001). Figure 4 compares the ILS (Equation 7) and ICS (calculated numerically) temperature response functions. For typical BHE diameters (100-200 mm) the ILS will underestimate the temperature response by over $10 \%$ for approximately the first half day of heating. For the first $6 \mathrm{~h}$ these errors will be in excess of $25 \%$.

For an infinite heat source the temperature change in the ground continues indefinitely. In reality, a steady state will be reached as 


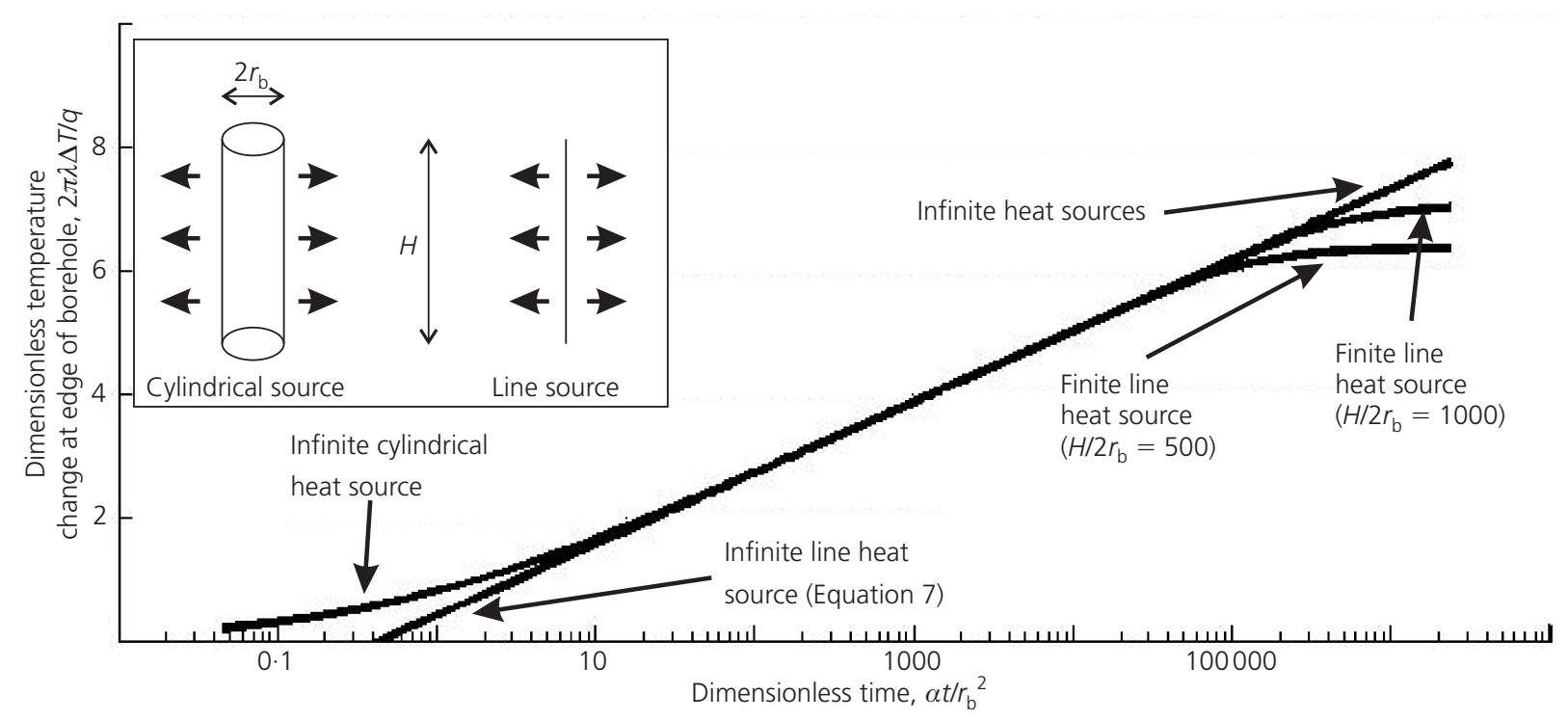

Figure 4. Dimensionless temperature response functions for heat exchanger design

heat extraction (or input) is matched by solar recharge (or losses) at the ground surface. Using a constant surface temperature boundary condition, Eskilson (1987) developed a finite line source (FLS) model using a combination of analytical and numerical approaches to derive a series of temperature response functions (termed $g$-functions) to take account of this effect. Figure 4 gives examples of FLS $g$-functions compared with the ICS and ILS temperature response functions. These show the ILS to overestimate temperature changes at large times; however, for typical boreholes which are longer than $100 \mathrm{~m}$, it will take over 30 years for these errors to reach 10\% (Philippe et al., 2009).

Eskilson (1987) also made an important step forward in BHE design by superimposing numerical solutions to account for interactions between different borehole installations. These multiple borehole $g$-functions, which now underpin a number of commercial software packages, allow designers to take account of the reduction in available thermal capacity when multiple heat exchangers are installed close enough together so that thermal interactions will occur between the individual heat exchangers.

All the preceding discussions assume a constant and continuous heat transfer rate $q$. In reality $q$ will vary with time according to the actual energy use in the building. Consequently the response will step from one temperature response curve to another depending on the actual value of $q$ at any one time.

\subsection{Internal response}

The heat exchanger is usually considered to be at a steady state (Bernier, 2001; Remund, 1999; Shonder and Beck, 1999; Xu and Spitler, 2006) and the estimated resistance is used to calculate the temperature change between the fluid and the borehole edge. The standard approach is to sum the resistances of the different components (Figure 3(b)), but this is a simplification as it can neglect contact resistances and pipe-to-pipe interactions. The former are usually assumed to be negligible, although there is a lack of research to confirm this. This simple approach also neglects the heat capacity of the borehole, although this is of minor significance for BHEs which would reach a steady state within a few hours.

Standard approaches for determining the resistance associated with the fluid $\left(R_{\text {pconv }}\right)$ and the pipe $\left(R_{\text {pcond }}\right)$ are well known (e.g. as described by Bernier (2001) and Marcotte and Pasquier (2008)) and are equally applicable to thermal piles. The effective resistance of the grout within a BHE is more complex and depends on the geometric positioning of the pipes with respect to the hole. Consequently common empirical approaches (e.g. Remund, 1999) cannot be applied to thermal piles and new methods are required.

\subsection{Fluid temperature profiles}

Simple design methods assume that the rate of heat transfer between the fluid and the borehole is constant around the length of the pipe circuit and hence with depth down the heat exchanger. For this to be the case, the fluid must lose heat (and therefore change temperature) at a constant rate around the pipe circuit (Figure 5(a)). Then, for a single U-tube installed in a borehole, the mean of the up and down fluid temperatures is constant with depth. However, numerical modelling (Lee and Lam, 2008; Marcotte and Pasquier, 2008) and field measurements (Acuna et al., 2009) show that a constant-temperature boundary condition (Figure 5(b)) is more representative of reality, and this results in an exponential variation in the fluid temperature with distance $x$ around the pipe circuit (Incropera et al., 2007) 


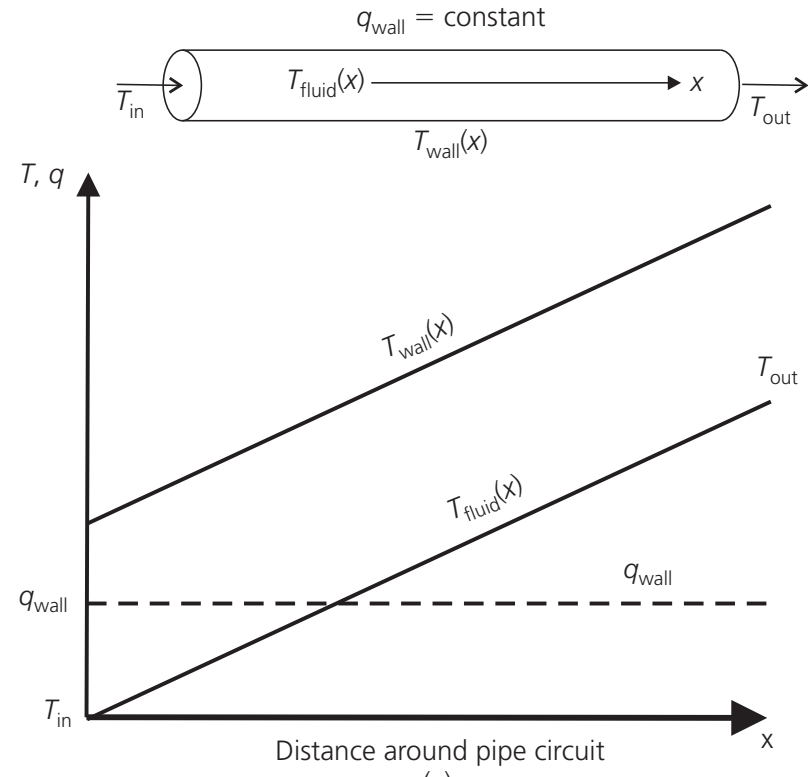

(a)
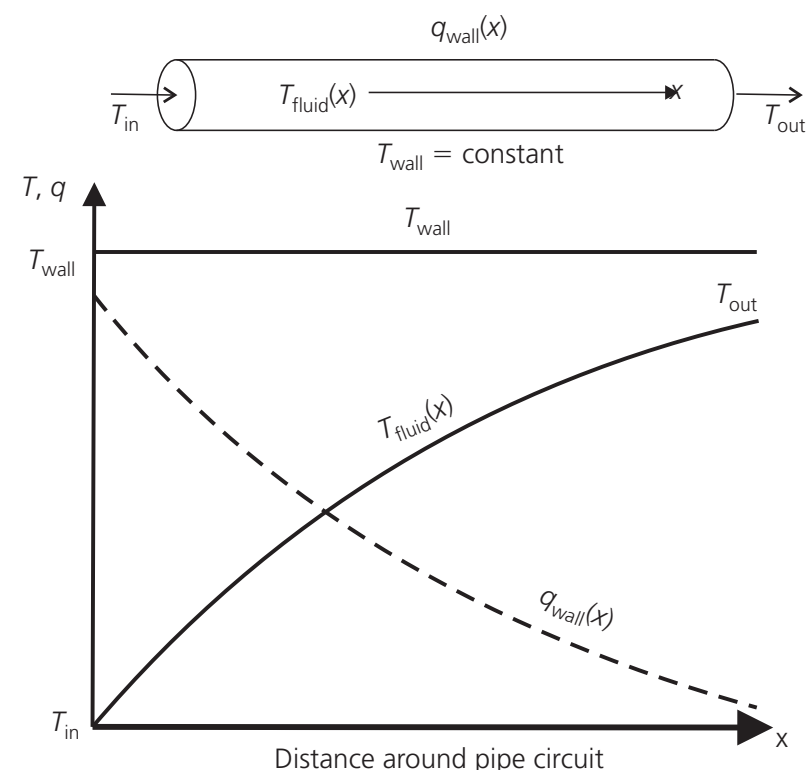

(b)

Figure 5. Boundary conditions and fluid temperatures profile for internal pipe flow: (a) constant heat transfer rate boundary condition; (b) constant temperature boundary condition

8. $\frac{T_{\mathrm{f}}-T_{\mathrm{b}}}{T_{\text {fin }}-T_{\mathrm{b}}}=\exp \left(\frac{-x}{2 R_{\mathrm{b}} m S_{\mathrm{c}}}\right)$

where $T_{\text {fin }}$ is the inlet fluid temperature and $m$ is the fluid mass flow rate. As a consequence the average fluid temperature for a single U-tube, and by extension the heat transfer rate, is not constant with depth (Figure 6).
Depending on the spacing of the two shanks of a U-tube, the two pipes may also exchange heat with each other (e.g. Diao et al., 2004a), thus reducing the efficiency of the system and increasing the variation of mean fluid temperature with depth (Figure 6). This is reflected in an increased borehole thermal resistance. Analytical solutions do exist for the calculation of the exact fluid temperature profile for a single U-tube (Diao et al., 2004a; Hellstrom, 1991); however, to implement these solutions allowing for interference between pipes is complex and requires knowledge of the precise internal geometry of the pipes within the borehole. Alternatively, an empirical solution for the fluid profile is available (Marcotte and Pasquier, 2008). However, this will not necessarily be appropriate for cases where significant interference occurs between the pipes, such as when they are touching (Lamarche et al., 2010).

\section{Thermal performance of pile heat exchangers}

\subsection{External thermal response}

There are very few data sets available for verification of the thermal design methods for piles used as heat exchangers. Published case studies often focus on the heat pump and overall system performance and do not consider the ground thermal response. This is unfortunate as the analytical approaches used for BHE (typically less than $200 \mathrm{~mm}$ diameter) design all have shortcomings when applied to larger-diameter thermal piles (typically at least $300 \mathrm{~mm}$ in diameter). Methods that assume a line source may be valid for small-diameter holes but for piled foundations, with the heat exchange pipes fixed near to the circumference steel, there will be errors for analysis periods of less than a few days or even months. Figure 4 shows these differences non-dimensionally, with divergence between the line and cylindrical source for non-dimensional time values of less than around 10. For a $600 \mathrm{~mm}$ diameter pile this translates to an underestimation of the temperature change by more than $10 \%$ for times up to 5 days, and by at least $25 \%$ for up to 2 days. For a $1.2 \mathrm{~m}$ diameter pile these times increase to 8 days and 21 days respectively. This underestimation of temperature changes is not conservative in terms of both the thermal capacity of the system and assessing the potential for adverse thermomechanical interactions (see Section 5).

For piles with heat exchanger pipes installed in the centre of the concrete then although the heat source may more closely approximate a line, there will be two regions (concrete and ground) with different thermal properties that need to be accounted for within the thermal design.

For short piles, a steady state may develop within a few years, rather than decades as with longer boreholes. For example, while for a $50 \mathrm{~m}$ long pile it may take 15-20 years for the error in the ILS solution to reach $10 \%$. The corresponding figure for a $20 \mathrm{~m}$ long pile is only 2 or 3 years. For domestic housing piles, typically around $10 \mathrm{~m}$ deep, this time can be less than a year. 

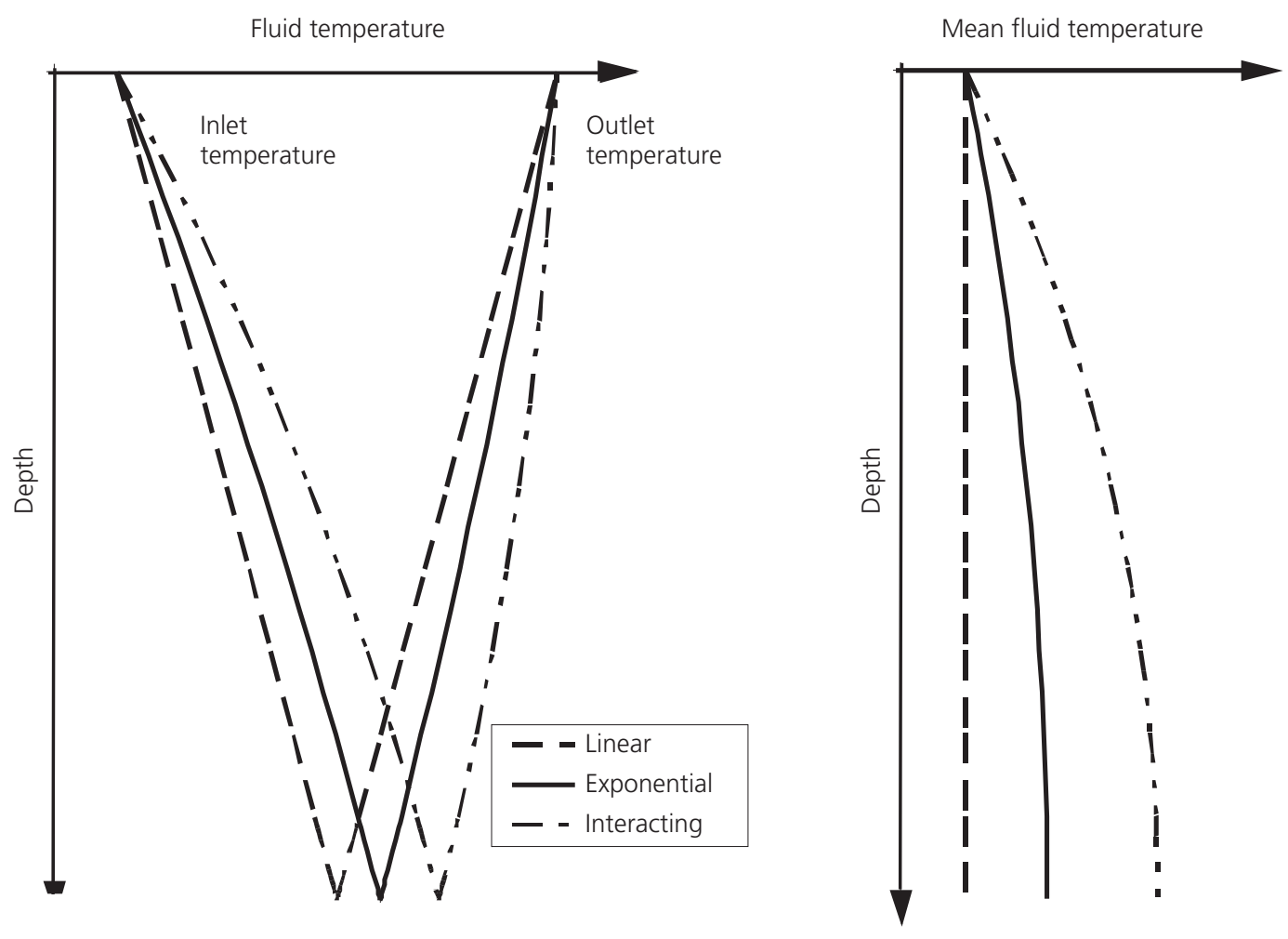

Figure 6. Fluid temperature profiles for a single U-tube in a vertical ground heat exchanger (calculated based on Equation 8 and the approach of Diao et al. (2004a) for interacting pipes)

This leads to a significant overestimation of the temperature response if an infinite source is assumed. This is conservative in terms of assessing thermomechanical interactions and thermal capacity; it does reduce the opportunities for maximising the thermal capacity of the system. Therefore it is important to use a model which considers the length of the piles when determining thermal performance.

The importance of the geometry of thermal piles is best indicated by the aspect (length to diameter) ratio (AR). Figure 7 shows aspect ratios for constructed thermal piles, which are generally in the range $10-50$, in contrast to values of 500-1000 typical for BHEs. Figure 8(a) shows how the aspect ratio of a thermal pile governs its temperature response function. Figure 8(b) highlights the differences between the ILS and a finite cylindrical heat source for four different aspect ratios. This shows the small time periods for which the ILS approach gives an acceptable error range when applied to thermal piles as applied to BHEs.

Some of the differences between the models discussed above may be less important for a truly thermally balanced system, where heat extraction continues for 6 months only and is then balanced by reinjection of surplus heat from air-conditioning systems.
However, it is rare for systems to be perfectly balanced and hence, depending on the actual weather conditions experienced and building usage, it is likely that there will be a net accumulation of heat (or cold) in the ground over time.

As a result of the potential for errors in predicting the ground thermal response at small and large times, considerable caution should be exercised when using any design software based on techniques developed for the assessment of BHEs. This has been highlighted by Wood et al. (2010a) who compared actual fluid inlet and outlet temperatures for a thermal pile test plot with values determined from commercial software using an FLS approach over a 1 -year period. While the overall trend calculated was reasonable, errors of about $2^{\circ} \mathrm{C}$ were apparent in the lower ranges of temperatures, with the design software underpredicting the fluid temperature. While this might not appear significant, systems tend to operate with small temperature differences and over small temperature ranges. For example, $2^{\circ} \mathrm{C}$ is $40 \%$ of the total temperature variation range presented by Wood et al. (2010a). In this context, and given the restrictions which need to be placed on systems to avoid ground freezing, an additional $2^{\circ} \mathrm{C}$ margin will reduce the efficiency of the system significantly.

A design approach which has been validated for use with thermal 


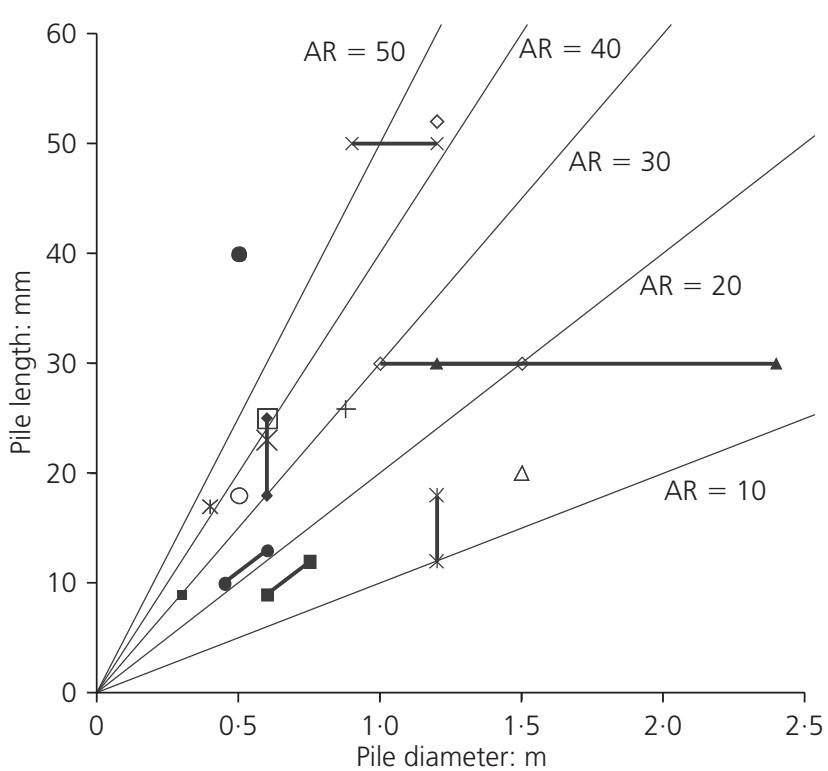

\begin{tabular}{|c|c|}
\hline 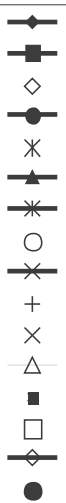 & $\begin{array}{l}\text { Pallant House, Chichester, UK } \\
\text { - Keble College, Oxford, UK } \\
\text { Bankside, London, UK } \\
\text { - Bolton Sixth Form College, UK } \\
\text { Bracknell College, UK } \\
\text { - One New Change, London, UK } \\
\text { - Rehabilitation centre, Austria } \\
\text { Multi-purpose hall, Austria } \\
\text { - Shopping centre, Austria } \\
\text { Swiss Federal Institute of Technology } \\
\text { Lambeth College, London, UK } \\
\text { University of Tokyo, Japan } \\
\text { House, Hokkaido, Japan } \\
\text { District heating scheme, Shanghai, China } \\
\text { Zurich Airport, Switzerland } \\
\text { Building, South China }\end{array}$ \\
\hline
\end{tabular}

Figure 7. Aspect ratios (denoted AR) of constructed thermal piles

piles is the so-called 'duct storage model' (DST) (Claesson and Hellstrom, 1981; Hellstrom, 1989). This assumes that a large number of vertical heat exchangers, or ducts, are installed close together to act as an underground thermal store. The model separates analysis of the local heat transfer around each duct from global heat transfer into and out of the thermal store. For local heat transfer an ILS is applied for short-duration heat pulses. Globally and at larger times (defined as when the individual ducts are thermally interacting) a steady state is assumed within the store and subsequent heat input leads to linear changes in temperatures throughout the store. The local and global solutions are then combined to assess the overall performance of the heat store. The DST was initially validated against field data for small-diameter $(<50 \mathrm{~mm})$ borehole thermal stores in Sweden (Hellstrom, 1983). Subsequently, the DST approach has been implemented specifically for use with thermal piles in the software 'PILESIM' (Pahud, 2007). PILESIM has been validated against thermal pile field data from Switzerland (Pahud and Hubbach, 2007), focusing on the overall heat exchange capacity of the system. Independent analysis using
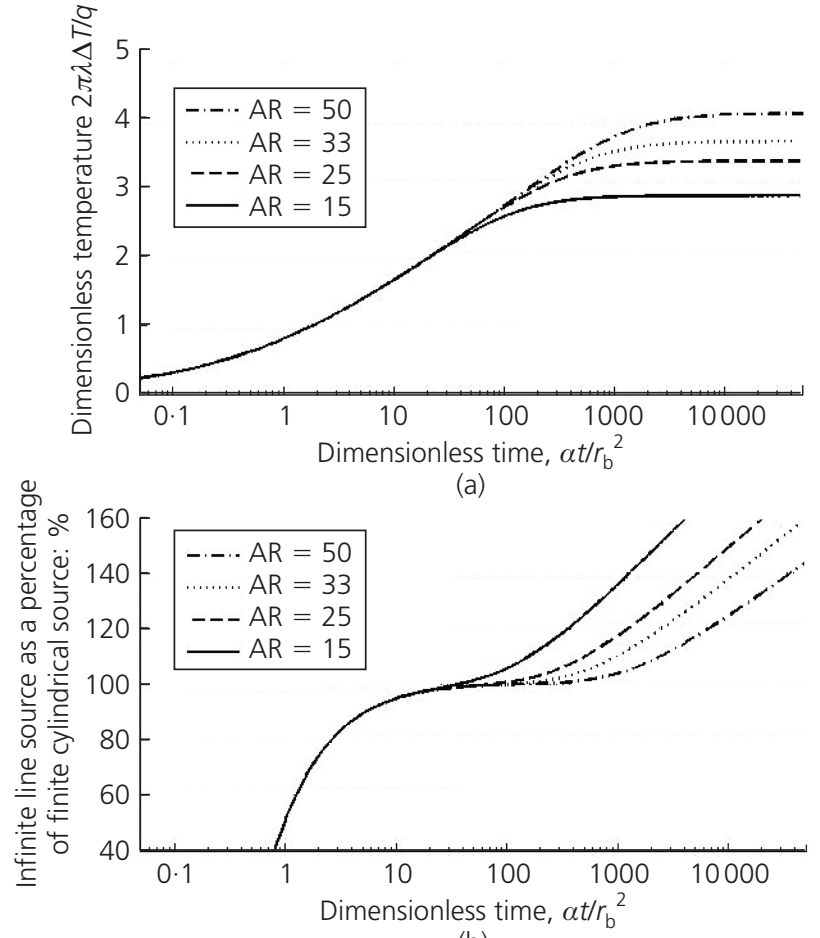

(b)

Figure 8. Effect of aspect ratio (AR) on ground temperature response function for thermal piles: (a) finite cylindrical source (ICS); (b) analytical methods as a percentage of ICS

time-stepping finite-element models (R. Markiewicz, personal communication, 2010) implies that for regular arrays of piles the results provided by Pilesim are appropriate. However, the DST assumes a large number of identical piles installed in a regular array within a circular plan area and it is not clear what errors result from smaller or less regular pile group arrangements that are more representative of typical foundation layouts.

The methods discussed above were all originally developed from the design of BHEs and assume a constant ground surface temperature equal to the initial average temperature in the ground. This neglects the seasonal variation of the ground surface temperature, which will affect the ground temperatures to about $10 \mathrm{~m}$ depth (Figure 2). For short, uncovered heat exchangers this can have a major influence on temperatures (Wood et al., 2009). For thermal piles covered by buildings, there will be no incoming solar radiation to recharge the ground temperature, but studies by Thomas and Rees (1999) show that buildings provide a small net heat flux to the ground and this may be a more appropriate longterm boundary condition. No current published methods of analysis take this into account and the topic requires further research to determine its importance.

\subsection{Thermal resistance for pile heat exchangers}

Theoretical values of $R_{\mathrm{b}}$ for thermal piles are given by the Swiss Society for Architects and Engineers (Table 2). These are 
Driven tube with double U-tube

Precast or cast in situ, with double U-tube attached to reinforcement Precast or cast in situ, with triple U-tube attached to reinforcement Precast or cast in situ, with quadruple U-tube attached to reinforcement

$\begin{array}{ll}0.3-0.5 & 0.15 \\ 0.3-1.5 & 0.1-0.11 \\ 0.3-1.5 & 0.07-0.08 \\ 0.3-1.5 & 0.06\end{array}$

Table 2. Pile thermal resistance values (after SIA (2005))

typically smaller, by up to a factor of 2, than published values derived from either in situ thermal testing or back-analysis of system operations (Table 3). This is likely to be due to the high values of thermal conductivity for concrete assumed in the Swiss analysis $\left(\lambda_{\mathrm{c}}=1.8 \mathrm{~W} / \mathrm{m} \mathrm{K}\right)$. In reality, for a heat exchange pile, $\lambda_{\mathrm{c}}$ is likely to be less than $1.5 \mathrm{~W} / \mathrm{m} \mathrm{K}$, owing to the high cement content required for strength and the presence of admixtures which can reduce thermal conductivity (Kim et al., 2003; Neville, 1995; Tatro, 2006). However, the thermal conductivity of concrete can be improved, for example by specification of siliceous aggregates.

The total thermal resistance of a pile would be expected to be larger than for a borehole (typically in the range $0.05-0.2 \mathrm{~m} \mathrm{~K} / \mathrm{W}$, Sanner et al. (2005)) based on the geometric arrangement of the pipes. As pile reinforcement must be protected from corrosion due to groundwater there tends to be a greater concrete cover to the pipes than for BHEs. This can lead to a larger resistance, especially if the pipes are actually in the centre of the pile. On the other hand, a greater number of pipes within the cross-section would lower the resistance.

$R_{\mathrm{b}}$ is usually calculated by the separate assessment of $R_{\mathrm{c}}, R_{\mathrm{pconv}}$ and $R_{\text {pcond }}$ (see Figure 3 ). Assuming turbulent flow, $R_{\text {pconv }}$ and $R_{\text {pcond }}$ tend to be small, in total around $0.01 \mathrm{~m} \mathrm{~K} / \mathrm{W}$ for four pipes in parallel, and easy to calculate (e.g. Bernier, 2001; Marcotte and Pasquier, 2008). $R_{\text {pconv }}$ depends on the flow conditions, captured in the heat transfer coefficient $h$ (Equation 1). The largest component of the thermal resistance of a pile is in the concrete or grout. This is more difficult to determine than the pipe resistance and depends on the arrangement of pipes and the concrete thermal conductivity. Currently, the most practical method for determining $R_{\mathrm{c}}$ is by numerical modelling.

Minimising the total thermal resistance of the pile is important for improving thermal performance and reducing the temperature gradient across the pile. This has been the subject of targeted research for borehole design and appropriate measures include ensuring that fluid flow is turbulent, using high thermal conductivity materials (Sanner et al., 2005) and installing more pipes within the hole (Gao et al., 2008; Zeng et al., 2003). For thermal piles, maximising the number of pipes and minimising the cover to those pipes are likely to be important factors. However, as the pile diameter increases, and especially for CFA-type piles with central pipes, the contribution of the pile to heat storage and not just transfer to the ground also increases. In such cases, a steadystate resistance may no longer be valid and a two-zone transient analysis of the concrete and ground response may be required. This area has seen little attention and requires further research.

\subsection{Fluid temperature profiles}

Heat transfer from the fluid to the edge of the pile depends on two factors: the resistance as discussed in Section 4.2 and the temperature difference. The latter depends on the flow conditions as described in Equation 8. Profiles of fluid temperature against distance along the pipe circuit, based on Equation 8 with a pile

\begin{tabular}{|c|c|c|c|c|}
\hline Pile diameter/type & Pipe arrangement & Total thermal resistance & Source & Comments \\
\hline $0.3 \mathrm{~m} \mathrm{CFA}$ & Single U-tube & $0.22 \mathrm{mK} / \mathrm{W}$ & $\begin{array}{l}\text { Wood et al. } \\
(2010 a)\end{array}$ & $\begin{array}{l}\text { Derived from combination of } \\
\text { analytical methods and back-analysis. } \\
\text { Laminar flow conditions }\end{array}$ \\
\hline $0.6 \mathrm{~m}$ cast in situ & $\begin{array}{l}\text { Single U-tube } \\
\text { Double U-tube in series } \\
\text { Triple U-tube in series }\end{array}$ & $\begin{array}{l}0.25 \mathrm{mK} / \mathrm{W} \\
0.15-0.2 \mathrm{mKM} \\
0.125-0.15 \mathrm{mK} / \mathrm{W}\end{array}$ & $\begin{array}{l}\text { Gao et al. } \\
(2008)\end{array}$ & $\begin{array}{l}\text { Bespoke thermal testing. Range of } \\
\text { values represents different flow rates } \\
\text { and connections between different U } \\
\text { tubes }\end{array}$ \\
\hline $0.27 \mathrm{~m}$ square driven & Single U-tube & $0 \cdot 17$ & Lennon & Short duration $(<30 \mathrm{~h})$ thermal \\
\hline $0.244 \mathrm{~m}$ drive steel tube & Single U-tube & $0 \cdot 11$ & et al. (2009) & response tests \\
\hline
\end{tabular}

Table 3. Pile thermal resistance values from in situ measurement or back-analysis 

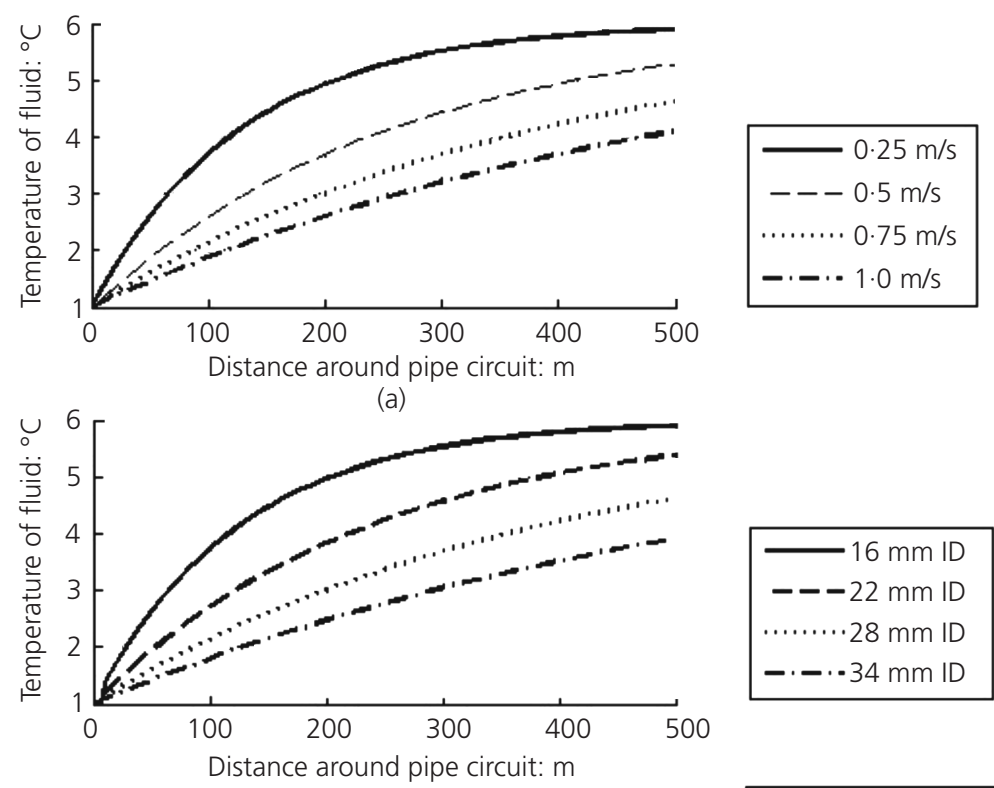

(b)
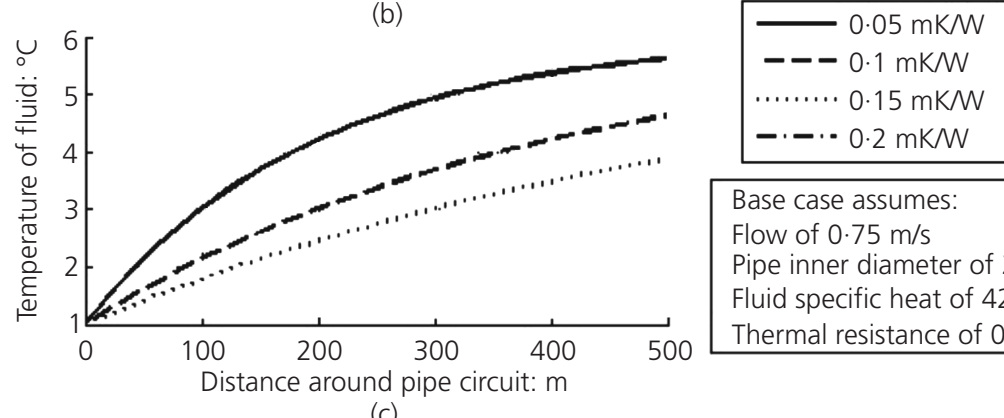

Base case assumes:

Flow of $0.75 \mathrm{~m} / \mathrm{s}$

Pipe inner diameter of $28 \mathrm{~mm}$

Fluid specific heat of $4200 \mathrm{~J} / \mathrm{kg} \mathrm{K}$

Thermal resistance of $0.1 \mathrm{mKN}$

(c)

Figure 9. Exponential fluid temperature variation in pipe circuits based on Equation 8 (assumes inlet temperature of $1^{\circ} \mathrm{C}$ and pile surface temperature of $6^{\circ} \mathrm{C}$ ): (a) sensitivity to flow rate;

(b) sensitivity to pipe size; (c) sensitivity to pile thermal resistance

surface temperature $T_{\mathrm{b}}=6^{\circ} \mathrm{C}$ and a fluid inlet temperature of $1^{\circ} \mathrm{C}$, are given in Figure 9. The effectiveness of heat transfer will reduce substantially as the temperature difference between the fluid and the outside boundary, $T_{\mathrm{b}}-T_{\mathrm{f}}$, reduces around the pipe circuit. For this reason it is best to keep the circuit length to a maximum of $300-400 \mathrm{~m}$ depending on the flow conditions (Figure 9). Maintaining a high flow rate (and high Reynolds number) will also maximise heat transfer regardless of circuit length. However, it should be noted that, practically, the pile circumference is unlikely to remain at a uniform temperature (as assumed in Equation 8), especially for low flow velocities where there is a large temperature difference between the inlet and the outlet.

As thermal piles are much shorter than boreholes, multiple piles are sometimes connected together into a single pipe circuit. Specific arrangements will depend on the number of pipes in a given cross-section. For example, while an installation of larger- diameter $50 \mathrm{~m}$ deep piles may contain six pipes as one circuit, an installation of shorter $25 \mathrm{~m}$ deep piles of smaller diameter with only four pipes may have three piles connected in series. In the latter case, the mean temperature of the fluid in each pile may vary significantly (Figure 10, right-hand side). Hence the temperature difference relative to the ground and also the heat transfer rate may be different for each pile. This has been observed by Wood et al. (2010b) where in a circuit comprising four $10 \mathrm{~m}$ deep piles connected in series the temperature difference between each successive pile was approximately $0 \cdot 5^{\circ} \mathrm{C}$. For longer circuits and deeper piles these differences may be more substantial; unsurprisingly, Wood et al. (2010b) found that the magnitude of the temperature difference decreases at higher fluid flow rate. What is not clear is how important these effects will be for overall performance of systems and hence further research is required in this area.

Thermal interactions between individual pipes will also affect the 

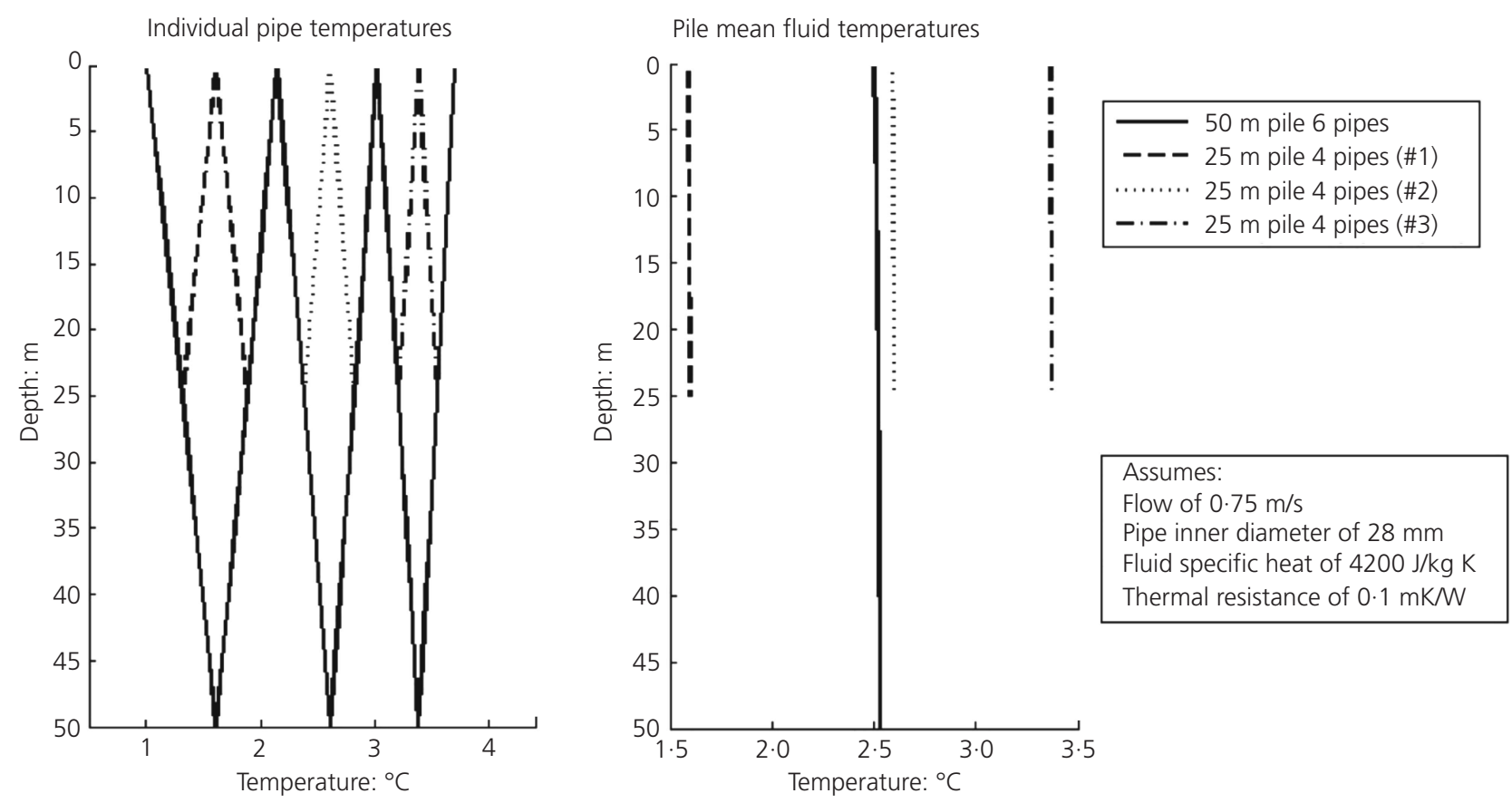

Figure 10. Example mean fluid temperatures for thermal piles connected in series (calculated using Equation 8 with inlet temperature of $1^{\circ} \mathrm{C}$ and pile surface temperature of $6^{\circ} \mathrm{C}$ )

fluid temperature profile and hence the heat transfer achieved. As the pipes in thermal piles tend to be fixed between the main steel of the pile cage, their separation is likely to be about 250$300 \mathrm{~mm}$ (P. Smith, personal communication, 2010) compared with less than $100 \mathrm{~mm}$ for typical boreholes. Consequently, less interaction between the pipes would be expected in piles than in boreholes. This is beneficial as it both maximises the heat transfer and reduces the thermal resistance. No field measurements of the fluid temperatures within the pipe circuits of thermal piles are known to have been carried out; only the inlet and outlet temperatures have been verified in situ.

Simulation of the fluid (water) temperature profile for a $16 \mathrm{~m}$ long, $1.2 \mathrm{~m}$ diameter pile with eight pipes installed in series has been carried out by Markiewicz (2004). The profiles are replotted here (Figure 11) in terms of non-dimensional temperature in keeping with Equation 8. An average borehole wall temperature had to be estimated from the published model results (Markiewicz, 2004). Curve-fitting for the profiles was then carried out as summarised in Table 4. This assessment shows that for high flow rates $(>1 \mathrm{~m} / \mathrm{s})$ the fluid profile is sufficiently close to a straight line to allow this simplified approach to be adopted (Figure 11(a)). An exponential curve of a form matching Equation 8 is appropriate for intermediate to high velocities, between about $0 \cdot 25 \mathrm{~m} / \mathrm{s}$ and $1 \mathrm{~m} / \mathrm{s}$ (Figure 11(b)). However, at low flow velocities $(<0.25 \mathrm{~m} / \mathrm{s})$, significant interference is observed with fluid near the end of the circuit relinquishing heat energy to that at the start of the circuit (Figures 11(c) and 11(d)). In such cases an exponential type curve is not appropriate. The interference also has a detrimental effect on the thermal resistance (Table 4), significantly reducing efficiencies of the pile as a heat exchanger. This illustrates the importance of maximising fluid flow rates while retaining pipe separation and limiting pipe circuit lengths in order to reduce interactions and hence facilitate maximum heat transfer.

\subsection{Groundwater flow}

Where groundwater is flowing, the temperature change in the ground adjacent to the heat exchanger will be reduced by additional advective heat transfer. While this is potentially a huge benefit in terms of the capacity of an individual ground energy system, the resulting thermal plume will travel a greater distance downstream giving the potential for interactions over a much wider area. This is evident from open-loop ground energy systems within aquifers beneath conurbations, where widespread adoption and extended use has led to significant changes in the aquifer temperatures (Ferguson and Woodbury, 2006; Gustafsson, 1993).

Design approaches for systems affected by groundwater are not well defined. Analytical solutions for the ground temperature response functions (Claesson and Hellstrom, 2000; Diao et al., 2004b; Sutton et al., 2003;) are based on the principle of an infinite line heat source moving through the medium being heated and thus 


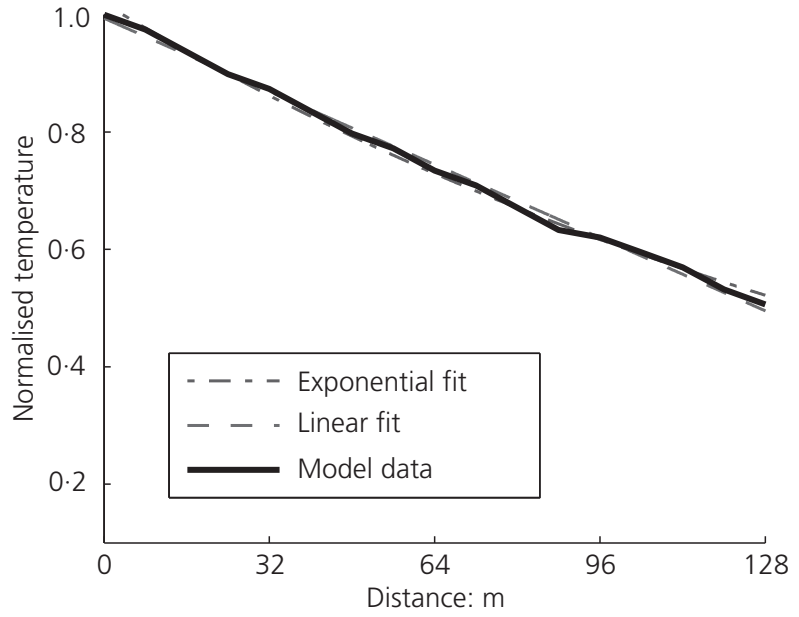

(a)

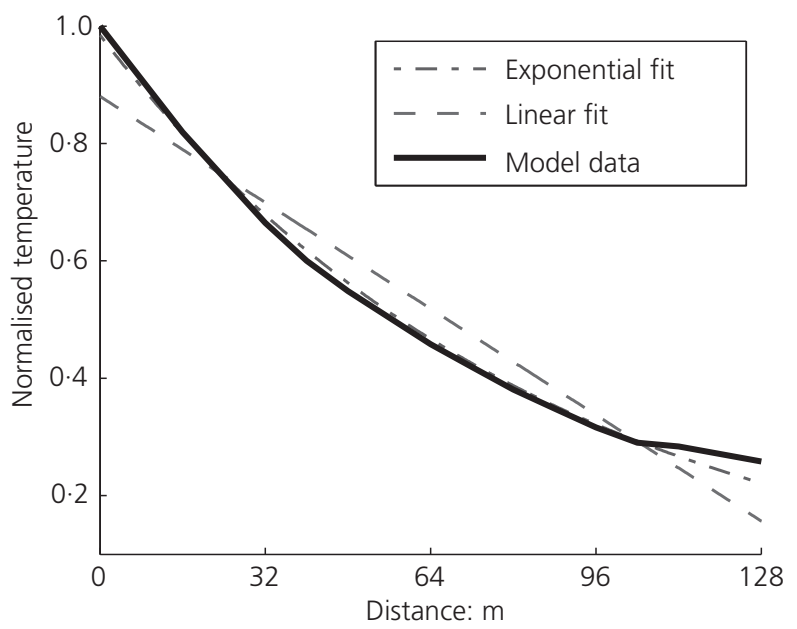

(c)

Figure 11. Normalised fluid temperature profiles from thermal pile modelling by Markiewicz (2004) (inlet temperature is $2^{\circ} \mathrm{C}$, borehole wall temperature taken as $1^{\circ} \mathrm{C}$ higher than outlet temperature based on results of original model. For curve-fit data refer to Table 4): (a) flow of $1 \mathrm{~m} / \mathrm{s}$; (b) flow of $0.5 \mathrm{~m} / \mathrm{s}$; (c) flow of $0.25 \mathrm{~m} / \mathrm{s}$; (d) flow of $0.1 \mathrm{~m} / \mathrm{s}$

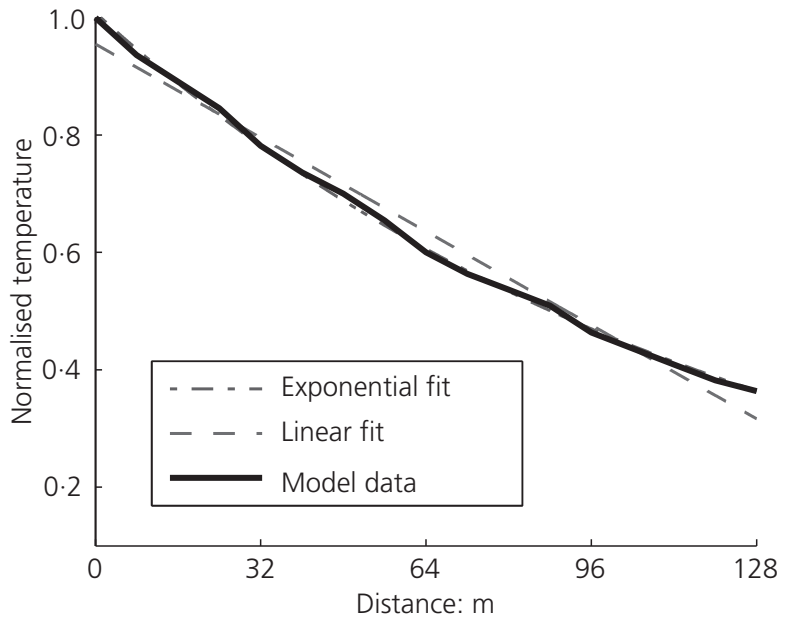

(b)

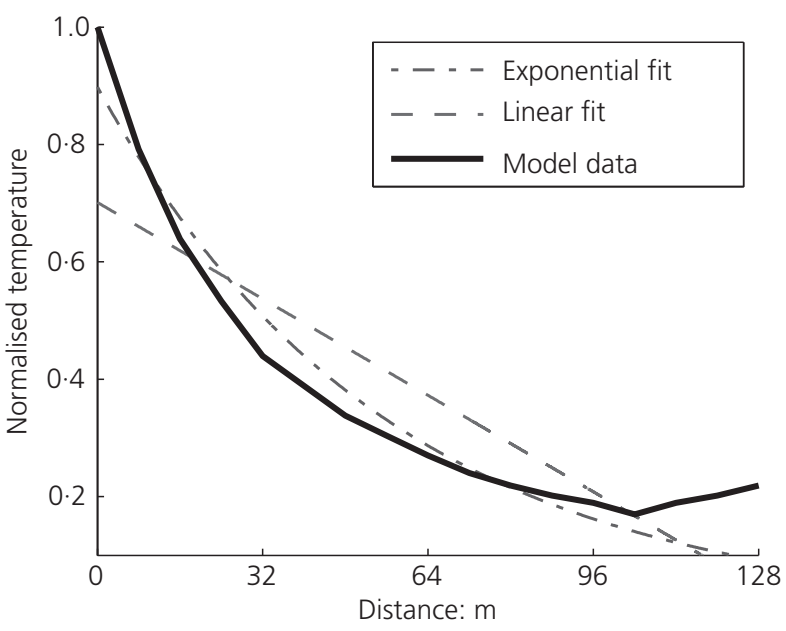

(d) disregard the development of a diffusive steady state. They also do not consider characteristics of real groundwater flow, including the effects of inhomogeneity and possible fracture flow. Consequently, numerical methods are often used to assess heat transfer in the presence of moving groundwater (e.g. Gehlin and Hellstrom, 2003; SIA, 2005). While it is important to question whether a sustained and consistent groundwater flow in an urban area can be relied upon over the design life of a system, any potential for adverse effects resulting from groundwater flow must also be assessed. In particular, the capacity for inter-seasonal energy storage will be reduced by flowing groundwater, which should be accounted for in any assessment of thermal potential.

\section{Thermomechanical interactions and pile behaviour}

The potential for adverse thermal interactions between heat exchanger piles and the ground has led to concerns that inappropriate operation may lead to ground freezing, excessive ground deformations or additional pile stresses that cannot be safely carried by the structure. Despite these fears, no mechanical or serviceability issues with thermal piles have been reported to date, possibly as a result of conservative design and geotechnical factors of safety providing capacity within which additional concrete stresses and displacements can be accommodated. However, such factors of safety are used to account for other 


\begin{tabular}{|c|c|c|c|c|c|c|c|}
\hline \multirow{2}{*}{$\begin{array}{l}\text { Flow: } \\
\mathrm{m} / \mathrm{s}\end{array}$} & \multirow[t]{2}{*}{ Curve type } & \multicolumn{2}{|c|}{ Coefficients } & \multirow{2}{*}{$\begin{array}{l}\text { Coefficient of } \\
\text { determination }\end{array}$} & \multirow{2}{*}{$\begin{array}{l}\text { Root mean } \\
\text { square error }\end{array}$} & \multirow{2}{*}{$\begin{array}{l}R_{\mathrm{b}}: \\
\mathrm{mKN}\end{array}$} & \multirow[t]{2}{*}{ Comments } \\
\hline & & $a$ & $b$ & & & & \\
\hline \multirow[t]{2}{*}{1} & $a x+b$ & -0.0039 & 0.9938 & 0.9968 & 0.0096 & & \multirow{4}{*}{$\begin{array}{l}\text { Linear and exponential curves provide good } \\
\text { and comparable fit } \\
\text { Exponential curve provides better fit and } \\
\text { temperature difference between inlet and } \\
\text { outlet increases }\end{array}$} \\
\hline & $a \exp (b x)$ & 1.019 & -0.005227 & 0.9965 & 0.0092 & 0.051 & \\
\hline \multirow[t]{2}{*}{0.5} & $a x+b$ & -0.0050 & 0.9551 & 0.9848 & 0.0258 & & \\
\hline & $a \exp (b x)$ & 1.008 & -0.007956 & 0.9988 & 0.0073 & 0.066 & \\
\hline \multirow[t]{2}{*}{$0 \cdot 25$} & $a x+b$ & -0.0056 & 0.8801 & 0.9938 & 0.0627 & & $\begin{array}{l}\text { Increased errors compared to higher } \\
\text { velocities }\end{array}$ \\
\hline & $a \exp (b x)$ & 0.945 & -0.01165 & 0.9957 & 0.0160 & 0.091 & $\begin{array}{l}\text { Some loss of fit at end of circuit due to } \\
\text { minor interference }\end{array}$ \\
\hline \multirow[t]{2}{*}{$0 \cdot 1$} & $a x+b$ & -0.0051 & 0.7012 & 0.7490 & $0 \cdot 1240$ & & Significantly greater errors for linear fit \\
\hline & $a \exp (b x)$ & 0.898 & -0.01783 & 0.9383 & 0.0615 & $0 \cdot 148$ & $\begin{array}{l}\text { Increased errors due to interference causing } \\
\text { poor fit }\end{array}$ \\
\hline
\end{tabular}

${ }^{a}$ Assuming $b=-1 /\left(2 R_{b} m S_{c}\right)$ and fluid and pipe properties as per Markiewicz (2004).

Table 4. Curve-fitting parameters for fluid profiles from

Markiewicz (2004), to be read in conjunction with Figure 11

uncertainties (e.g. ground heterogeneity) and therefore this is not a satisfactory design approach.

Consequently, it is important that the potential for additional thermal stresses is assessed and temperature limits placed on ground energy systems to prevent structures from experiencing temperature variations which would adversely affect the geotechnical performance. The following sections discuss the theoretical framework for thermal-mechanical interactions, what can be learnt from recent case studies, and uncertainties that still remain, especially with respect to long-term cyclic loading. As temperature changes resulting from ground energy systems only occur after the building is complete and operational, the discussion will exclude early-age thermal effects in concrete. This is in keeping with recent research which argues that for piles in saturated ground, creep and shrinkage effects are insignificant compared with other loads (Bicocchi, 2011).

\subsection{Behavioural framework}

In principle, when a thermal pile is heated it will tend to expand and when it is cooled it will tend to contract. Free expansion or contraction will not occur because the pile is restrained, both by the surrounding soil and by any overlying structure. Consequently a proportion of the theoretical free strain will be expressed instead as a change in longitudinal stress within the pile and transferred to the ground by skin friction or end bearing. A pile that expands relative to the surrounding soil will tend to experience an increase in the axial stress (termed hereafter the 'pile axial load'), and a pile that contracts a reduction: however, the exact effect will vary, and could even be locally reversed along the length of the pile depending on the degree and nature (resilience) of the end restraints. A similar observation applies to the mobilised skin friction. Potential concerns include overstressing the cross-section, an excessive increase in base bearing pressure, or the development of negative (downward) skin friction resulting potentially in the loss of external load-carrying capacity. A useful conceptual framework for assessing this complex behaviour has been presented by Bourne-Webb et al. (2012) and illustrates in particular the importance of the end restraints in controlling the thermomechanical response. This framework can be used to assess potential thermal effects in terms of additional forces that should be accommodated in design. However, case studies are important for validation of the approach.

\subsection{Lessons from case studies}

Early observations of strain and temperature within a thermal pile were reported by Brandl (1998). While the study did not give sufficient detail to enable a full assessment of the thermomechanical behaviour, it does illustrate the consequences of excessive heat extraction. As fluid temperatures reached $-5^{\circ} \mathrm{C}$, ice lenses formed within the ground, causing $150 \mathrm{~mm}$ of heave at the surface. Relative movement between the pile and the ground would also have been expected to have altered the shaft skin friction.

This case study illustrates the importance of ensuring that the pile and ground do not freeze. The simplest way of achieving this is to specify that the fluid temperature must not fall below $0^{\circ} \mathrm{C}$. Given that the fluid temperature varies around the pipe circuit and that measurement errors are possible, a safety margin is typically also allowed for. Specification of minimum fluid temperature of $2^{\circ} \mathrm{C}$ is therefore recommended by some bodies 
(NHBC, 2010; SIA, 2005). However, this is a conservative approach and will result in a failure to utilise the ground to its full thermal potential. Therefore a more sophisticated approach may be adopted whereby assessment of the pile thermal resistance and fluid temperature profiles can be made to demonstrate that lower fluid outlet temperatures will not lead to development of freezing conditions at the soil-pile interface. As well as this assessment, it is important that a suitable building control system is in place to prevent lower temperature limits from being exceeded in the case of a higher than expected heating demand.

Two systematic attempts to assess the thermomechanical response of thermal piles have recently been made. A working pile for a new building at the Swiss Federal Institute of Technology was used for thermomechanical testing, reported by Laloui et al. $(1999,2006)$ and summarised in Table 5. Before construction of the building a simple thermal test was carried out and the resulting temperature changes and strain data used to calculate the mobilised skin friction. For a $22^{\circ} \mathrm{C}$ temperature increase the pile expanded by $4 \mathrm{~mm}$ at the head, with a small amount of compression at the toe reflecting the high end restraint due to the embedment of the pile in hard sandstone. Near uniform heating caused between $30 \mathrm{kPa}$ and $80 \mathrm{kPa}$ of skin friction to develop in different soil layers. Further heating of the pile was carried out under different pile head loads (Table 5). The pile was constrained, both at the toe (by bedrock) and at its head (by the structure). Pile axial loads of up to $2 \mathrm{MN}$ were induced over the full length, the largest of which were over the lower portion of the pile. This additional thermal load was greater than the mechanical pile axial load of $1.3 \mathrm{MN}$ at the pile head (Table 5). However, given the pile restraint, the corresponding additional pile head displacements were small; less than $2 \mathrm{~mm}$ of heave was recorded.

A thermomechanical load test was carried out on a sacrificial test pile at Lambeth College in London (Bourne-Webb et al., 2009). The pile was subjected to separate heating and cooling cycles while carrying an external mechanical load of $1200 \mathrm{kN}$ at the head (Table 5), equivalent to the anticipated working load. The heating caused an increase in pile axial load of up to $800 \mathrm{kN}$ in the upper part of the pile, while the cooling cycle led to a reduction in load of about $500 \mathrm{kN}$, mainly near the base of the pile. This smaller (up to about $70 \%$ of the original external load) and less even distribution of additional pile axial load compared with the Swiss test is due to the lower degree of restraint of the Lambeth College pile. Again the accompanying changes in pile head displacement were small at less than $2 \mathrm{~mm}$ (Table 5). The consequent changes in shaft friction were estimated to be up to about $50 \mathrm{kPa}$, with a maximum total of $75 \mathrm{kPa}$ developing during the thermal tests, compared with a value in excess of $90 \mathrm{kPa}$ developed at the ultimate limit state in subsequent destructive load testing.

Both tests indicated the thermomechanical response of the thermal pile to be largely reversible, and the pile-soil system to be acting thermo-elastically, at least over small numbers of cycles. This elastic behaviour was confirmed when a new approach for calculating the effects of thermal loading on piles using an elastic load transfer method was tested on the above case studies (Knellwolf et al., 2011). In addition to providing a good match to the experiment data, the method of Knellwolf et al. went on to assess a number of possible working scenarios. It

\begin{tabular}{|c|c|c|c|c|}
\hline \multirow{2}{*}{$\begin{array}{l}\text { Reference } \\
\text { Test }\end{array}$} & \multicolumn{2}{|c|}{ Bourne-Webb et al. (2009) } & \multirow{2}{*}{$\begin{array}{l}\text { Laloui et al. (1999) } \\
\text { Operational pile - one } \\
\text { storey constructed }\end{array}$} & \multirow{2}{*}{$\begin{array}{l}\text { Laloui et al. (2006) } \\
\text { Operational pile - seven } \\
\text { stories constructed }\end{array}$} \\
\hline & Test pile - cooled & Test pile - heated & & \\
\hline Pile length & \multicolumn{2}{|l|}{$23 \mathrm{~m}$} & \multicolumn{2}{|l|}{$25 \cdot 8 \mathrm{~m}$} \\
\hline Pile diameter & \multicolumn{2}{|l|}{$0.6 \mathrm{~m}$} & \multicolumn{2}{|l|}{$0.88 \mathrm{~m}$} \\
\hline Ground conditions & \multicolumn{2}{|c|}{$\begin{array}{l}\text { Made ground and river terrace deposits to } 5 \mathrm{~m} \\
\text { overlying London Clay }\end{array}$} & \multicolumn{2}{|c|}{$\begin{array}{l}\text { Alluvium to } 12 \mathrm{~m} \text {, glacial till to } 25 \mathrm{~m} \text {, toed into } \\
\text { sandstone }\end{array}$} \\
\hline Restraint & \multicolumn{2}{|l|}{ Non-significant } & \multicolumn{2}{|c|}{ Large seven-storey building and piled toed into rock } \\
\hline Temperature change & -15 to $-20^{\circ} \mathrm{C}$ & +5 to $+10^{\circ} \mathrm{C}$ & $+22^{\circ} \mathrm{C}$ & $+13^{\circ} \mathrm{C}$ \\
\hline Head load & $1200 \mathrm{kN}$ & $1200 \mathrm{kN}$ & $300 \mathrm{kN}$ & $1300 \mathrm{kN}$ \\
\hline Mechanical load & $\begin{array}{l}+1200 \text { kN near head, } \\
\text { zero at toe }\end{array}$ & $\begin{array}{l}+1200 \text { kN near head, } \\
\text { zero at toe }\end{array}$ & $+300 \mathrm{kN}$ at head & $\begin{array}{l}+1300 \mathrm{kN} \text { at head, zero at } \\
\text { toe }\end{array}$ \\
\hline Thermal load & $\begin{array}{l}\text { Zero at head, }-300 \mathrm{kN} \\
\text { near base }\end{array}$ & $\begin{array}{l}+800 \mathrm{kN} \text { at } 4 \mathrm{~m} \\
+200 \mathrm{kN} \text { at base }\end{array}$ & $+1000 \mathrm{kN}$ at head & $\begin{array}{l}+1200 \mathrm{kN} \text { at head, } \\
+2000 \mathrm{kN} \text { at toe }\end{array}$ \\
\hline $\begin{array}{l}\text { Additional pile head } \\
\text { displacement }\end{array}$ & $-2 \mathrm{~mm}$ & $+2 \mathrm{~mm}$ & $<+2 \mathrm{~mm}$ & $<+1 \mathrm{~m}$ \\
\hline
\end{tabular}

Table 5. In situ measurements of pile thermomechanical

reponses 
was shown that for a pile where the head load induces skin friction close to the ultimate capacity, additional heating may cause the ultimate skin friction capacity to be reached. Conversely, cooling of the pile can cause a reversal of shear stresses and the development of negative skin friction.

The observed reversible nature of the thermal-mechanical behaviour is encouraging as the range of temperatures used in the testing is realistic compared to likely operational ranges, thereby suggesting that permanent deformation is unlikely to result from operation of ground energy systems. However, short-term testing cannot identify smaller cyclic effects that could become significant over longer timescales and larger numbers of cycles. Thus longer-term, in situ trials and/or laboratory testing will be required to confirm the soil-structure behaviour over the lifetime of a system, likely to be in excess of 25 years.

\subsection{Soil thermal behaviour and cyclic loading effects}

The above discussion has focused solely on the potential for volume change and induced stresses within the concrete pile. However, the temperature changes will also result in volume change in the soil and potentially in changes to the soil properties. Volume changes may occur due to both thermal expansion and temperature-induced mechanical changes to the soil structure. For normally or lightly over-consolidated clay soils, heating usually results in contraction and consolidation and large settlements are possible (Boudali et al., 1994). For highly overconsolidated clays, however, elastic expansion is typical and the overall effect on the soil is small (Cekerevac and Laloui, 2004). However, most investigations of thermally driven volume change in soils have focused on heating clays to high temperatures to simulate conditions relevant to nuclear waste disposal. The effect of smaller magnitude cycles of heating and cooling over a number of years has yet to be investigated.

Most studies of cyclic loading of piles relate to offshore structures. Poulos (1988) provides a useful discussion in this respect and highlights that two-way cyclic loading, as would probably be the case for thermal piles, is more damaging. Beyond a threshold cyclic load, typically close to the static load required to cause pile-soil slip, degradation of the shaft skin friction can occur (Poulos, 1989). Reduction in skin friction by up to $20 \%$ has been recorded (Jardine, 1991) but any individual case will depend on the soil properties, the nature of the pile, the static and cyclic loads and the loading rate. Full assessment of behaviour can be made if appropriate laboratory tests have been carried out, but caution must be exercised as thermal piles will be subject to a more uniform (with length) loading than offshore piles where the axial load is concentrated at the head.

Laloui and Cekerevac (2008) suggest that the number of mechanical load cycles required to fail a test specimen increases with temperature. Soil strength tests at elevated temperatures show varying results, but any deterioration of peak or critical state friction angle over the range of temperatures relevant to ground energy systems is likely to be small (Laloui, 2001); hence a significant reduction in the ultimate shaft capacity due to a general change in temperature is unlikely. Again, however, the effect of longer-term cyclic changes should be investigated further.

\section{Practical constraints}

The foregoing discussions relate to largely theoretical aspects of thermal pile behaviour. However, there are many design and construction interfaces which will affect any thermal pile scheme. While for traditional ground energy systems the layout of the heat exchangers is optimised to maximise thermal output, for thermal piles, the structural and geotechnical design will take priority. This means that the aim is to determine the thermal capacity from a given pile layout and also to check the thermomechanical effects on the geotechnical design. It is unlikely to be economic to install additional piles or increase their lengths purely to provide additional energy capacity. The ground conditions and any natural variability in their thermal properties are also a given parameter that must be accounted for in the thermal design. Currently it is usual for average thermal properties to be used in design regardless of the soil complexity. This is despite the fact, known from studies of BHEs, that stratified soil conditions can cause differences in behaviour between heating and cooling (Signorelli et al., 2007).

To some extent the layout of fluid pipes can be optimised once the pile layout has been determined. The number of pipes installed and their positions will be determined by the thermal design, as long as this is compatible with the construction process. For example with a full-depth cage the number of pipes and their locations and pipe circuit lengths can relatively easily be adjusted to maximise thermal output. However, if the pile is to be constructed by CFA techniques or has a cage over only part of its length, then it is likely that this will force installation of the pipes within the centre of the pile. It is also essential to ensure that any pipes fixed to cages during the construction process are fixed using a safe system of working and this has encouraged the placement of pipes on the outside of cages (Figure 1(a)).

If possible it will be advantageous to use concrete with a high thermal conductivity. This would mean maximising the aggregate content and using higher-conductivity aggregates such as sandstone. However, practically, the mix design is driven by the structural strength and slump requirements and it will always be more economic and more sustainable to use local sources of aggregate than to import special materials from greater distances.

Whereas construction of piles for building developments usually only interfaces with the groundworks contractor, thermal piles and the pipes which come from them have far more design and construction interfaces. It is important to protect pipes from damage at all stages of construction, from breaking out the piles, to extending the pipes beneath the building slab and ultimately to the plant room. It is essential to have redundancy in the system in case of damage during construction, but this should be coordi- 
nated by all the parties which interface with the ground energy system in order to prevent overconservatism. Pressure testing of the pipes to confirm integrity at key construction stages is essential for managing this process.

\section{Conclusion}

The ground is well suited to act as a thermal store and using structural piled foundations as heat exchangers is an increasingly common approach to improving the energy efficiency and reducing the carbon emissions from new buildings. The design of thermal piles has two distinct components: assessment of available heating and cooling capacity and additional checks as part of the geotechnical design to ensure that the cycles of temperature change do not have an adverse effect on the geotechnical design.

Assessment of heating and cooling capacities has often followed similar approaches to those used for the design of BHE arrays. However, care must be taken as the smaller aspect ratio of piles compared with boreholes means that thermal piles will reach a steady state more quickly. Consequently analytical methods which assume an infinite heat source will overestimate the temperature change in the ground. While conservative, in terms of assessing both the available heat output and the potential for adverse thermomechanical interactions, this approach will result in the thermal potential of the ground not being maximised. Consequently, it could potentially lead to systems being assessed as uneconomic. One of the few validated design approaches for estimating the thermal response of the ground to thermal piles is based on the duct storage model. However, this method assumes that all the piles are installed on a regular grid and it is not clear what uncertainties are introduced from more realistic pile layouts.

Thermal piles will also be significantly influenced by their internal thermal behaviour - in particular, the size of the pile, the amount of concrete cover to the pipes, and the relative positions and number of the pipes within the pile which can cause internal heat transfer. These factors are usually accounted for by the pile thermal resistance. However, there are no standard methods available for calculating the thermal resistance of piles, leading to uncertainty regarding parameter selection. The few published values of pile resistance have been derived principally from in situ tests. However, the discrepancy between these values and theoretical values suggests that more research is required in this area.

Thermal resistance is also influenced by the temperature profile of the heat exchanger fluid, which may vary non-linearly around the heat exchanger circuit. There are two typical scenarios for thermal piles, one with pipes placed around the circumference of the pile (attached to the steel cage) and one with the pipes placed centrally within the pile. The former is beneficial and will have a lower resistance as the pipes are closer to the ground. However, in the latter case there will be a large resistance, the pipes are more likely to interact adversely and questions remain as to whether a steady state approach to the pile behaviour is appropriate. These topics all warrant further research in order to assist more efficient heat exchanger design.

When multiple piles are connected in series, the change in heat transfer rate along the length of the pipe circuits can lead to each pile in the series having a different heat transfer rate to the ground. This is not accounted for in standard thermal design methods and the importance of this effect is still not known. All these uncertainties in the assessment of thermal capacity are exacerbated by the lack of high-quality monitoring data from case studies with which to validate potential new approaches.

\section{Acknowledgements}

This work has been funded by Mott MacDonald and the Engineering and Physical Sciences Research Council (EP/ H049010/1). The authors would also like to thank Peter Smith of Cementation Skanska for his useful discussion on construction details.

\section{REFERENCES}

Acuna J, Mogensen P and Palm B (2009) Distributed thermal response test on a U-pipe borehole heat exchanger. Proceedings of the 11th International Conference on Thermal Energy Storage for Efficiency and Sustainabiltiy, Effstock, Stockholm, Sweden, 14-17 June, paper No. 18.

Banks D (2008) An Introduction to Thermogeology: Ground Source Heating and Cooling. Blackwell, Oxford, UK.

Bernier M (2001) Ground coupled heat pump system simulation. ASHRAE Transactions 107(1): 605-616.

Bicocchi N (2011) Structural and Geotechnical Interpretation of Strain Gauge Data from Laterally Loaded Reinforced Concrete Piles. PhD thesis, University of Southampton, UK.

Bose JE, Parker JD and McQuiston FC (1985) Design/Data Manual for Closed Loop Ground Coupled Heat Pump Systems. American Society of Heating, Refrigeration and Air Conditioning Engineers, Atlanta, GA, USA.

Boudali M, Leroueil S and Srinivasa MBR (1994) Viscous behaviour of natural clays. Proceedings of the 13th International Conference on Soil Mechanics and Foundation Engineering, New Delhi, India, 411-416.

Bourne-Webb PJ, Amatya B, Soga K et al. (2009) Energy pile test at Lambeth College, London: geotechnical and thermodynamic aspects of pile response to heat cycles. Géotechnique 59(3): 237-248.

Bourne-Webb P, Amatya B and Soga K (2012) A framework for understanding energy pile behaviour. Proceedings of the Institution of Civil Engineers - Geotechnical Engineering Available online at http://dx.doi.org/10.1680/geng.10.00098.

Brandl H (1998) Energy piles and diaphragm walls for heat transfer from and into the ground. In Proceedings of the $3 \mathrm{rd}$ International Conference on Deep Foundations on Bored and Auger Piles, Ghent (Van Impe WF and Haegeman W (eds)). AA Balkema, Rotterdam, the Netherlands, pp. 37-60.

Brandl H (2006) Energy foundations and other thermo active ground structures. Géotechnique 56(2): 81-122. 
Busby J, Lewis M, Reeves H and Lawley R (2009) Initial geological considerations before installing ground source heat pump systems. Quarterly Journal of Engineering Geology and Hydrogeology 42(3): 295-306.

Carslaw HS and Jaeger JC (1959) Conduction of Heat in Solids, 2nd edn. Oxford University Press, Oxford, UK.

Cekerevac C and Laloui L (2004) Experimental study of thermal effects of the mechanical behaviour of a clay. International Journal for Numerical and Analytical Methods in Geomechanics 28(3): 209-228.

Chiasson AC, Rees SJ and Spitler JD (2000) A preliminary assessment of the effects of groundwater flow on closed loop ground source heat pump systems. ASHRAE Transactions 106(1): 380-393.

CIBSE (Chartered Institute of Building Service Engineers) (2005) Current CIBSE TRY/DSY Hourly Weather Data Set - London. CIBSE, London, UK.

Claesson J and Hellstrom G (1981) Model studies of duct storage systems. In Proceedings of the International Conference on New Energy Conservation Technologies and their Commercialisation (Millhone JP and Willis EH (eds)). International Energy Agency, Berlin, Germany.

Claesson J and Hellstrom G (2000) Analytical studies on the influence of regional groundwater flow on the performance of borehole heat exchangers. In Proceedings of the 8th International Conference on Thermal Energy Storage, Terrastock 2000, Stuttgart, Germany (Benner M and Hahne E (eds)). University of Stuttgart, Institute of Thermodynamics and Thermal Engineering, Stuttgart, Germany, vol. 1, pp. 195-200.

Coulson JM and Richardson JF (1990) Chemical Engineering, Volume 1, Fluid Flow, Heat Transfer and Mass Transfer, 4th edn. Pergamon Press, Oxford, UK.

Diao NR, Zeng HY and Fang ZH (2004a) Improvements in modelling of heat transfer in vertical ground heat exchangers. $H V A C \& R$ Research 10(4): 459-470.

Diao NR, Li Q and Fang Z (2004b) Heat transfer in ground heat exchangers with groundwater advection. International Journal of Thermal Sciences 43(12): 1203-1211.

Eskilson P (1987) Thermal Analysis of Heat Extraction Boreholes. $\mathrm{PhD}$ thesis, Department of Mathematical Physics, University of Lund, Sweden.

Ferguson GF and Woodbury AD (2006) Observed thermal pollution and post development simulations of low temperature geothermal systems in Winnipeg, Canada. Hydrogeology Journal 14(7): 1206-1215.

Gao J, Zhang X, Liu J, Li K and Yang J (2008) Numerical and experimental assessment of thermal performance of vertical energy piles: an application. Applied Energy 85(10): 901-910.

Gehlin SEA and Hellstrom G (2003) Influence on thermal response test by groundwater flow in vertical fractures in hard rock. Renewable Energy 28(14): 2221-2238.

Gustafsson O (1993) Sweden. In The Hydrogeology of the Chalk of North-West Europe (Downing RA, Price M and Jones GP (eds)). Clarendon Press, Oxford, UK.
Hellstrom G (1983) Comparison between theoretical models and field experiments for ground heat systems. In Proceedings of the International Conference on Subsurface Heat Storage in Theory and Practice, Stockholm. Swedish Council for Building Research, Stockholm, Sweden, vol. 2.

Hellstrom G (1989) Duct Ground Heat Storage Model, Manual for Computer Code. Department of Mathematical Physics, University of Lund, Sweden.

Hellstrom G (1991) Ground Heat Storage, Thermal Analysis of Duct Storage Systems, Theory. Department of Mathematical Physics, University of Lund, Sweden.

Incropera FP, Dewitt DP, Bergman TL and Lavine AS (2007) Fundamentals of Heat and Mass Transfer, 6th edn. Wiley, Hoboken, NJ, USA.

Ingersoll LR, Zobel OJ and Ingersoll AC (1954) Heat Conduction with Engineering and Geological Applications, 3rd edn. McGraw-Hill, New York, NY, USA.

Jardine RJ (1991) The cyclic behaviour of large piles with special reference to offshore structures. In Cyclic Loading of Soils from Theory to Design (O'Reilly MP and Brown SF (eds)). Blackie, Glasgow, UK.

Kavanaugh SP and Rafferty K (1997) Design of Geothermal Systems for Commercial and Institutional Buildings. American Society of Heating Refrigeration and AirConditioning Engineers, Atlanta, GA, USA.

Kim KH, Jeon SE, Kim JK and Yang S (2003) An experimental study on thermal conductivity of concrete. Cement and Concrete Research 33: 363-371.

Knellwolf C, Peron H and Laloui L (2011) Geotechnical analysis of heat exchanger piles. Journal of Geotechnical and Geoenvironmental Engineering, 137(10): 890-902.

Laloui L (2001) Thermo-mechanical behaviour of soils. Revue Française de Génie Civil 5(6): 809-843.

Laloui L and Cekerevac C (2008) Non-isothermal plasticity model for cyclic behaviour of soils. International Journal for Numerical and Analytical Methods in Geomechanics 32(5): 437-460.

Laloui L, Moreni M, Fromentin A, Pahud D and Vulliet L (1999) In-situ thermo-mechanical load test on a heat exchanger pile. In Proceedings of the 4th International Conference on Deep Foundation Practice Incorporating Piletalk, Singapore. Deep Foundations Institute, Hawthorne, NJ, USA. pp. 273-279.

Laloui L, Nuth M and Vulliet L (2006) Experimental and numerical investigations of the behaviour of a heat exchanger pile. International Journal for Numerical and Analytical Methods in Geomechanics 30(8): 763-781.

Lamarche L, Kajl S and Beauchamp B (2010) A review of methods to evaluate borehole thermal resistance in geothermal heat pump systems. Geothermics 39(2): 187-200.

Lee CK and Lam HN (2008) Computer simulation of borehole ground heat exchangers for geothermal heat pump systems. Renewable Energy 33(6): 1286-1296.

Lennon DJ, Watt E and Suckling TP (2009) Energy piles in Scotland. In Proceedings of the 5th International Conference on Deep Foundations on Bored and Auger Piles, Frankfurt 
(Van Impe WF and Van Impe PO (eds)). Taylor and Francis, London, UK.

Marcotte D and Pasquier P (2008) On the estimation of thermal resistance in borehole thermal conductivity test. Renewable Energy 33(11): 2407-2415.

Markiewicz R (2004) Numerical and Experimental Investigations for Utilization of Geothermal Energy Using Earth-coupled Structures and New Developments for Tunnels. PhD thesis, Vienna University of Technology, Austria.

Neville AM (1995) Properties of Concrete, 4th edn. Longman, London, UK.

NHBC (2010) Efficient Design of Piled Foundations for Low Rise Housing, Design Guide. NHBC Foundation, Milton Keynes, UK.

Pahud D (2007) PILESIM2, Simulation Tool for Heating/Cooling Systems with Heat Exchanger Piles or Borehole Heat Exchangers, User Manual. Scuola Universitaria Professionale della Svizzera Italiana, Lugano, Switzerland.

Pahud D and Hubbach M (2007) Mesures et Optimisation de l'Installation avec Pieux Energétiques du Dock Midfield de l'Aéroport de Zurich. Office fédéral de l'energie, Ittigen, Switzerland, final report.

Philippe M, Bernier M and Marchio D (2009) Validity ranges of three analytical solutions to heat transfer in the vicinity of boreholes. Geothermics 38(4): 407-413.

Poulos HG (1988) Marine Geotechnics. Unmin Hyman, London, UK.

Poulos HG (1989) Pile behaviour - theory and application. Géotechnique 39(3): 365-415.

Preene M and Powrie W (2009) Ground energy systems from analysis to geotechnical design. Géotechnique 59(3): 261271.

Rees SW, Adjali MH, Zhou Z, Davies M and Thomas HR (2000) Ground heat transfer effects on thermal performance of earth contact structures. Renewable and Sustainable Energy Reviews 4(3): 213-265.

Remund CP (1999) Borehole thermal resistance: laboratory and field studies. ASHRAE Transactions 105(1): 439-445.

Sanner B, Hellstrom G, Spitler J and Gehlin SEA (2005) Thermal response test - current status and world-wide application. In Proceedings of the World Geothermal Congress, Antalya, Turkey. International Geothermal Association, Bochum, Germany.

Shonder JA and Beck JV (1999) Determining effective soil formation properties from field data using a parameter estimation technique. ASHRAE Transaction 105(1): 458-466.

SIA (2005) Utilisation de la Chaleur du Sol par des Ouvrages de Fondation et de Soutènement en Béton, Guide pour la Conception, la Réalisation et la Maintenance. Swiss Society of Engineers and Architects, Documentation D 0190.

Signorelli S, Bassetti S, Pahud D and Kohl T (2007) Numerical evaluation of thermal response tests. Geothermics 36(2): 141-166.

Sutton MG, Nutter DW and Couvillion RJ (2003) A ground resistance for vertical bore heat exchangers with groundwater flow. Journal of Energy Resources Technology 125(September): 183-189.

Tatro SB (2006) Thermal properties. In Significance of Tests and Properties of Concrete and Concrete Making Materials (Lamond J and Pielert J (eds)). Portland Cement Association, Stokoie, IL, USA.

Thomas HR and Rees SW (1999) The thermal performance of ground floor slabs - a full scale in situ experiment. Building and Environment 34(2): 139-164.

VDI (2009) Thermal Use of the Underground - Ground Source Heat Pump Systems. The Association of German Engineers (VDI), Dusseldorf, Germany, VDI 4640, Part 2.

Wood CJ, Liu H and Riffat SB (2009) Use of energy piles in a residential building, and effects on ground temperature and heat pump efficiency. Géotechnique 59(3): 287-290.

Wood CJ, Liu H and Riffat SB (2010a) Comparison of a modeled and field tested piled ground heat exchanger system for a residential building and the simulated effect of assisted ground heat recharge. International Journal of Low Carbon Technologies 5(12): 137-143.

Wood CJ, Liu H and Riffat SB (2010b) An investigation of the heat pump performance and ground temperature of a pile foundation heat exchanger system for a residential building. Energy 35(12): 3932-3940.

Xu X and Spitler JD (2006) Modelling of vertical ground loop heat exchangers with variable convective resistance and thermal mass of fluid. Proceedings of the 10th International Conference on Thermal Energy Storage - EcoStock 2006, Pomona, NJ, USA, paper 4A-3.

Zeng H, Diao N and Fang Z (2003) Heat transfer analysis of boreholes in vertical ground heat exchangers. International Journal of Heat and Mass Transfer 46(23): 4467-4481.

\section{WHAT DO YOU THINK?}

To discuss this paper, please email up to 500 words to the editor at journals@ice.org.uk. Your contribution will be forwarded to the author(s) for a reply and, if considered appropriate by the editorial panel, will be published as a discussion in a future issue of the journal.

Proceedings journals rely entirely on contributions sent in by civil engineering professionals, academics and students. Papers should be 2000-5000 words long (briefing papers should be 1000-2000 words long), with adequate illustrations and references. You can submit your paper online via www.icevirtuallibrary.com/content/journals, where you will also find detailed author guidelines. 